\title{
Concept design and dynamic analyses of a floating vertical-axis wind turbine: case study of power supply to offshore Greek islands
}

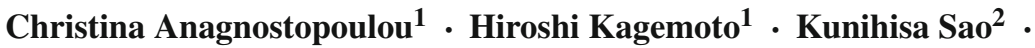 \\ Akisato Mizuno ${ }^{3}$
}

Received: 25 November 2014 / Accepted: 25 July 2015 / Published online: 21 August 2015

(C) Springer International Publishing AG 2015

\begin{abstract}
Concept design of floating wind turbines consisting of a column-supported semi-submersible and a verticalaxis wind turbine are proposed. Detailed motion response analyses of the proposed floating wind turbines are carried out using a computer program developed in this study. Together with wave-induced oscillatory motions, steady and slowly varying motions induced by waves and winds are also examined. As a case study, the feasibility of power supply to offshore Greek islands from the proposed floating wind turbines is examined.
\end{abstract}

Keywords Wind energy · Floating wind turbine - Verticalaxis wind turbine $\cdot$ Offshore wind farm $\cdot$ Aegean Sea

\section{Introduction}

In order to reduce the massive $\mathrm{CO}_{2}$ emission from conventional fossil fuel thermal power plants and/or to reduce the dependence on nuclear power plants, utilization of natural renewable energies is now being strongly promoted worldwide. Among various candidates of possible natural energy resources, wind power is considered to be one of the most promising resources along with solar power.

Introduction of wind power plants has been particularly active in Europe, in which, as the result of the massive deploy-

\section{Hiroshi Kagemoto}

kagemoto@k.u-tokyo.ac.jp

1 Graduate School of Frontier Sciences, The University of Tokyo, 1-5-1 Kashiwanoha, Kashiwa, Chiba 277-8561, Japan

2 Ocean Engineering Research Inc., 503 Koshin Build., Takadanobaba, Shinjuku-ku, Tokyo 169-0075, Japan

3 Kogakuin University, 1-24-2 Nishi-shinjuku, Shinjuku-ku, Tokyo 163-8677, Japan ment of wind power plants, little land space is now available for further wind power generation. In addition, wind noises associated with the rotation of blades of wind power generators have now become a new environmental problem.

In order to mitigate these problems, offshore wind power generation is now being actively promoted, and offshore wind farms consisting of an array of a large number of wind turbines are being constructed or planned in many places worldwide. As an offshore wind turbine, there could be two types, that is, a bottom-fixed type and a floating type. Between them, in the present study, the authors focus on a floating one, which is advantageous over a bottom-fixed one as the water depth becomes greater, and examine its feasibility as a preliminary study.

One of the problems associated with the power (electricity) generation at an offshore wind farm is the high cost of power cables used for the power transmission to a land area. Considering this problem, in this study, the authors examine the feasibility of power supply to grid-remote islands from an offshore wind farm deployed in the vicinity of the corresponding islands, which could not only mitigate the high cost of power transmitting cables but also ensure the energy supply and independence of those islands through renewable energy resources. As a case study, this paper chooses the Aegean islands of offshore Greece, where power demands increase sharply in summer due to a large inflow of people visiting from all of Europe.

\section{Concept design of a floating wind turbine}

\subsection{Basic requirements}

Design of a wind turbine and a floating structure is carried out to meet the following requirements. 
Table 1 Principal particulars of the SWVAWT

\begin{tabular}{ll}
\hline Rated power & $2 \mathrm{MW}$ \\
Rated wind speed & $12 \mathrm{~m} / \mathrm{s}$ \\
Power coefficient (electricity) & 0.318 \\
Power coefficient (turbine) & 0.461 \\
Wing span & $63.5 \mathrm{~m}$ \\
Wing cord length & $7.94 \mathrm{~m}$ \\
Number of wings & 3 \\
Rotation diameter & $95.3 \mathrm{~m}$ \\
Tip speed ratio & 3.75 \\
\hline
\end{tabular}

1. High efficiency of wind power generation

The power coefficient of the designed wind turbine was estimated to be $\mathrm{Cp}=0.318$. The performance of the wind turbine including the power coefficient was estimated numerically (Shibuya 2006) by the two-stage multiple streamtubes method (Paraschivoiu 1988). The wing section is NACA-0018, which is a symmetrical shape. Numerical simulation using sliding mesh with a turbulence model of DES was also carried out in order to obtain the performance of the turbine (Wakisaka 2011). These two approaches gave good agreement on a 2-D basis. The main specifications described in Table 1 were obtained by these numerical analyses.

The power coefficient of our vertical axis wind turbine (VAWT), that is, $\mathrm{Cp}=0.318$ may not be higher than that of conventional horizontal-axis wind turbines (HAWTs), but, if compared to the generated power to cost ratio, the present VAWT is of significantly better performance than conventional HAWTs.

2. Long natural period to realize small motions

Preferably longer than $30 \mathrm{sec}$. in all six modes of motion.

3. Small inclination (trim and heel) in survival condition (for safety) and in operating condition (for power generation) Preferably less than $5^{\circ}$, even in survival condition.

4. Small size of a floating structure

In this study, firstly, the rated power of the wind power generator is assumed to be $2 \mathrm{MW}$. The size of the floating structure is then determined in the design procedure while requiring that the structure could support the wind power generator safely with possible minimum size, preferably around $100 \mathrm{~m}$ in the main dimensions in order to minimize the cost.

5. Feasible mooring system

Mooring systems are designed so that the following requirements are satisfied.

1. Mooring lines can withstand the expected maximum (static + dynamic) stresses.

2. Natural periods of all six modes of motions are longer than $30 \mathrm{~s}$ to eliminate the resonance with waves.

\subsection{Type of the wind turbine considered}

Although most of the existing offshore wind turbines are 'horizontal axis' wind turbines, the present study chooses a 'vertical axis' wind turbine in order to exploit the following advantages of vertical axis wind turbines.

1. The structure is simpler.

Because there needs to be no taper, there is no screw to the blade, which leads to lower cost of construction. Also a VAWT does not have a yawing mechanism, nor a pitch control mechanism, which are generally equipped in large scale HAWTs. Moreover, maintenance of a VAWT is easier because of less moving parts, and, thus, the management cost can be reduced.

2. Lower noise.

3. Gyroscopic effect is small.

As will be shown later numerically, the gyroscopic effect due to the rotation of blades of a VAWT on the dynamic responses of a supporting floating structure is small.

4. No response delay to the change of wind direction.

5. Pitch control of the blades is not necessary.

The authors understand that most of HAWTs of the size of $2 \mathrm{MW}$ are equipped with a pitch control mechanism to attain higher performance. On the other hand, for a VAWT, blade pitch control is not necessary, if a control system is properly equipped so that appropriate tip speed ratio is maintained according to wind speed change.

6. The center of gravity can be lowered.

7. Maintenance can be done easily.

Since the VAWT proposed in the present study does not have such moving parts as yaw mechanism or pitch control, less mechanical troubles are expected. It is also easier to inspect the blade surfaces such as for paint deterioration because the blades are straight and not twisted.

These are the advantages of VAWTs as compared to HAWTs. Although the power coefficient itself of a VAWT is not necessarily better than that of a HAWT (e.g., Ashwill 1992), the simpler structures of VAWTs are expected to lead to significant cost reduction, though an explicit quantitative cost reduction estimation is not possible at the present stage.

As a floating wind turbine, the fact that a VAWT can flexibly change the ratio of its horizontal and vertical dimensions in complying with the stability requirement as a floating structure may also be advantageous over a HAWT.

Jonkman (2007) and Jonkma and Matha (2011) carried out dynamic analyses of three concepts of offshore floating HAWTs, that is, HAWTs supported on a TLP (Tension Leg Platform), a spar buoy, and a barge and compared their performances. Detailed reviews of the possible application of VAWTs to offshore floating turbines and the methods for their dynamic analyses in marine environmental conditions 
Fig. 1 Possible mooring systems of a floating wind turbine

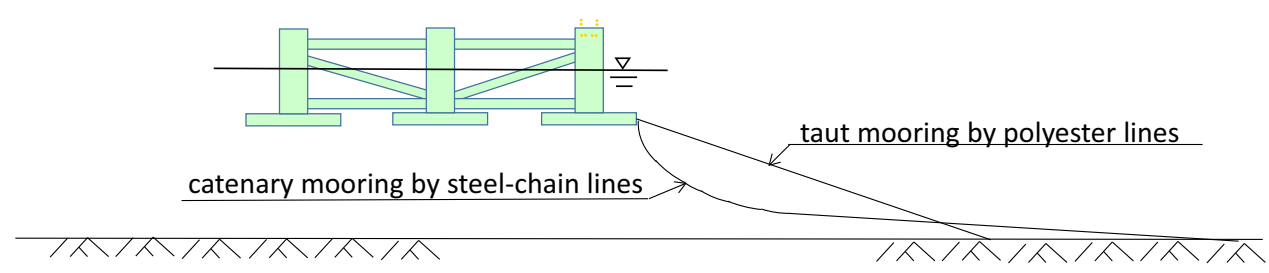

were carried out by Borg et al. (2014a, b and 2015). There also already exist several studies conducted on the feasibility of floating VAWTs such as those by Blonk (2010) and by Fowler et al. (2014), but the present study focuses more on the feasibility from the viewpoint of the dynamic behaviors of a floating VAWT. As will be shown later, the numerical methods used for the dynamic analyses of VAWTs in this study are mostly based on conventional ones.

For a vertical axis wind turbine, a vertical axis turbine with straight wings (SWVAWT) is considered in this study. Compared to conventional vertical axis wind turbines such as a Darrieus-type one, the SWVAWT is more efficient because the whole length of each wing is exploited for the power generation, while, in a Darrieus-type turbine, the parts around the upper and lower edges of its wings are not effectively used for the power generation, and, thus, the blade length of the wind turbine could be smaller than that of a conventional vertical axis wind turbine of the same rated capacity.

The principal particulars of the SWVAWT assumed in this study are shown in Table 1. The wing section is NACA-0018, which is a symmetrical shape.

\subsection{Floating structure}

Water depth at the installation site affects the type of a floating structure. The present study assumes the water depth is 100 $300 \mathrm{~m}$.

As for the floating structure on which the SWVAWT is installed, possible candidates may be (1) column-supported semi-submersible (2) tension-leg platform (3) spar buoy, and (4) barge. Among them, from the viewpoint of the reduction of wave-induced motions, a semi-submersible, a tension-leg platform and a spar buoy could be candidates. (A barge-type floating structure with an additional motion damping mechanism such as a moonpool could also be possible, but is not considered in this study.)

Preliminary design of a semi-submersible supporting a 5 MW HAWT was conducted by Lefebvre and Collu (2012). In this study, also, a semi-submersible is chosen as a floating structure on which a SWVAWT is mounted.

\subsection{Mooring system}

In the water depth considered in the present study (100$300 \mathrm{~m}$ ), if steel chains are used, in order to ensure appropriate restoring forces, a mooring system of long chains is needed, which, in turn, exerts large forces at the attachment points of the mooring lines on the structure due to their large weight and also could induce significant displacements/inclinations of the corresponding semi-submersible because of its small waterplane area. If polyester mooring lines are used instead of steel chains, such a burden can be reduced, because its weight in water can be almost zero. Besides, the restoring force characteristics of polyester mooring lines are linear, and, thus, the design of the mooring system is relatively easy.

On the other hand, little restoring forces are induced by polyester mooring lines if they are deployed as catenary lines, because their weight in water is small. Therefore, they need to be deployed as taut lines as shown in Fig. 1 to secure substantial restoring forces, which, in turn, could shorten the natural period of motions excessively. In this respect, steelchain catenary mooring lines are advantageous over polyester taut mooring lines in that natural periods of motions could be made much longer than the periods of relevant component waves of the wave power spectrum representing the corresponding offshore area, where the corresponding floating structure is to be deployed.

\subsection{Designed floating wind turbine}

As a floating wind turbine, two possible ones, that is, a wind turbine supported on a triangular-type 3-column semisubmersible (Fig. 2) and that supported on a triangular-type 4-column semi-submersible (Fig. 3) were designed.

The design was carried out following the design procedure shown in Fig. 4 while considering the design requirements described in Sect. 2.1. In the design process, various structure sizes and/or mooring systems were studied, and the steel structure weight, which is roughly proportional to the construction cost, was estimated. Finally, the main particulars of the structure were decided based on the criterion of cost minimization. The principal particulars and the values of relevant parameters of the designed two semi-submersibles are 


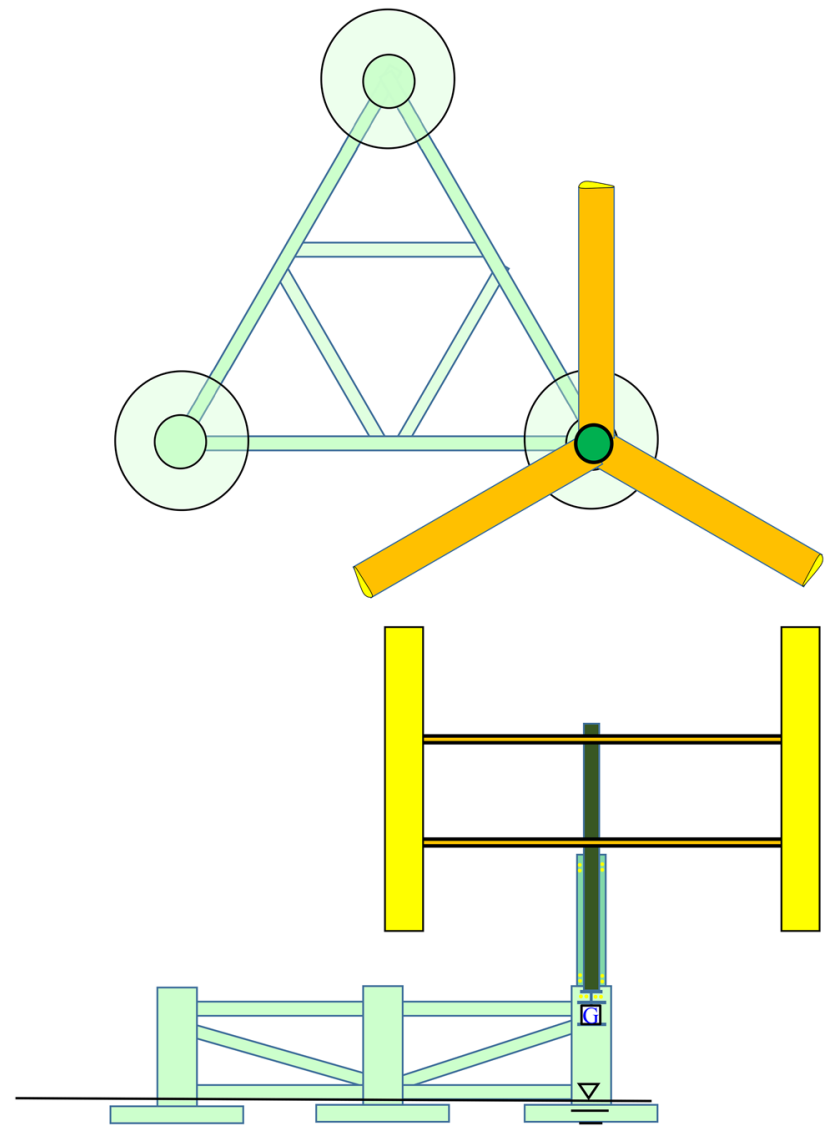

Fig. 2 A vertical-axis wind mill supported on a 3-column semisubmersible

shown in Tables 2 and 3, respectively. The values shown in the tables are those obtained while using roughly estimated values of hydrodynamic forces and so on. The more accurate values are obtained by more elaborate numerical simulations, as will be shown later in this paper.

As shown in Figs. 2, 3, on the 3-column semi-submersible, a wind turbine is supposed to be deployed on one of the 3 columns consisting of a triangular array, while, on the 4column semi-submersible, a wind turbine is supposed to be deployed on the center column of the 4-column array. From the viewpoint of construction and/or maintenance works, the former one is desirable in that the required reach of a working crane used for the placement or replacement of a heavy wind turbine is shorter, which, in turn, reduces the necessary capacity of the crane. As for the construction cost, in general, the construction cost of a 4-column semi-submersible is higher than that of a 3-column semi-submersible because of its larger structural weight.

On the other hand, the 3-column system that has a relatively small displacement may be needed to be moored by steel-chain catenary lines in order that the natural periods of motions are larger than the period range of the relevant wave power spectrum representing the deployment site. In
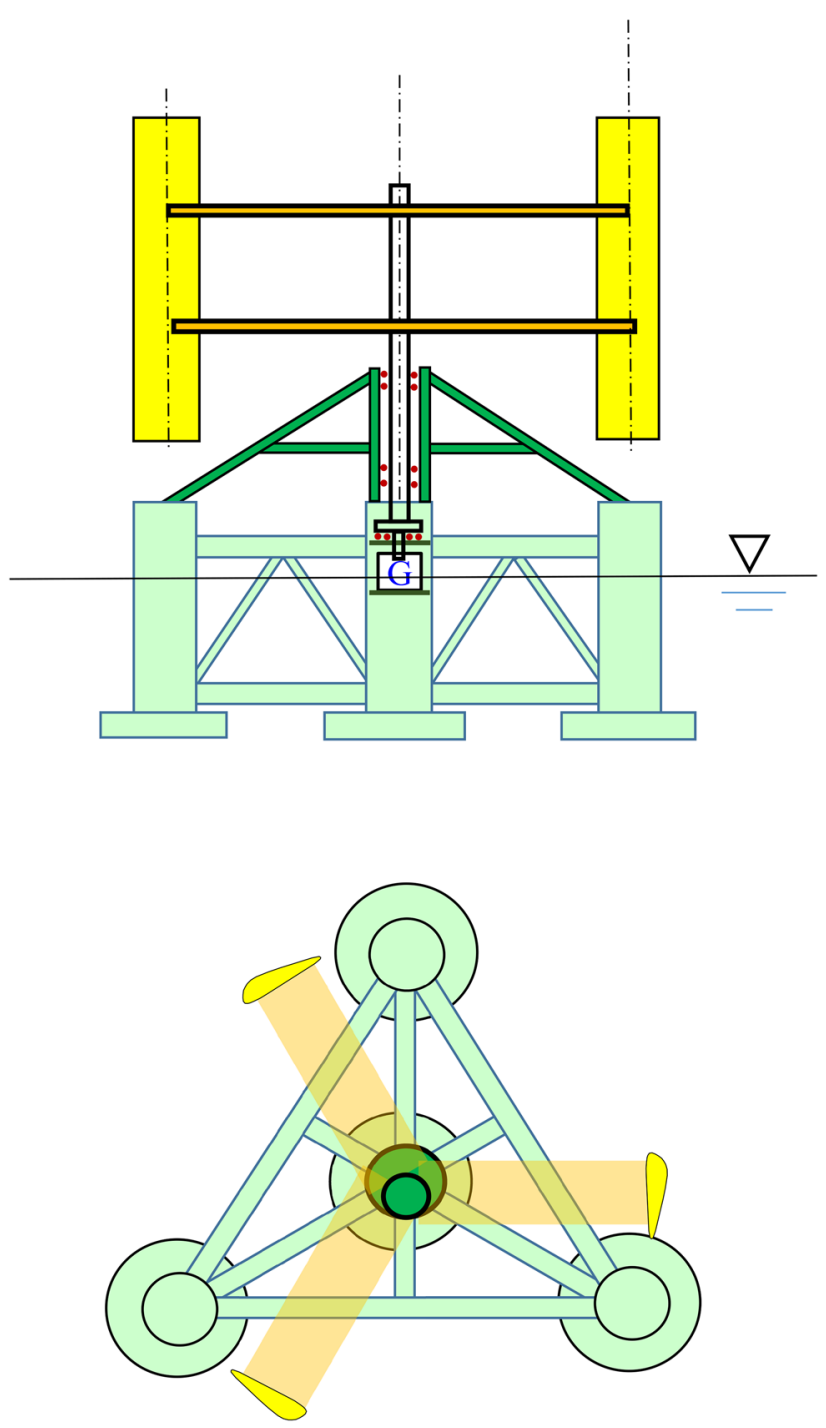

Fig. 3 A vertical-axis wind mill supported on a 4-column semisubmersible

this respect, the 4-column system could be moored by taut polyester lines because of its relatively large weight.

In the dynamic analyses shown later in this paper, the possibility of the deployment of both the steel-chain catenary mooring system and the polyester taut mooring system were examined for both the 3-column semi-submersible and the 4-column semi-submersible.

\section{Development of a computer code for dynamic analyses of floating wind turbines}

To evaluate the various performances of the designed system, a computer program was developed for frequency domain and time domain analyses in waves, wind, and current. The following summarizes the main specifications of the devel- 


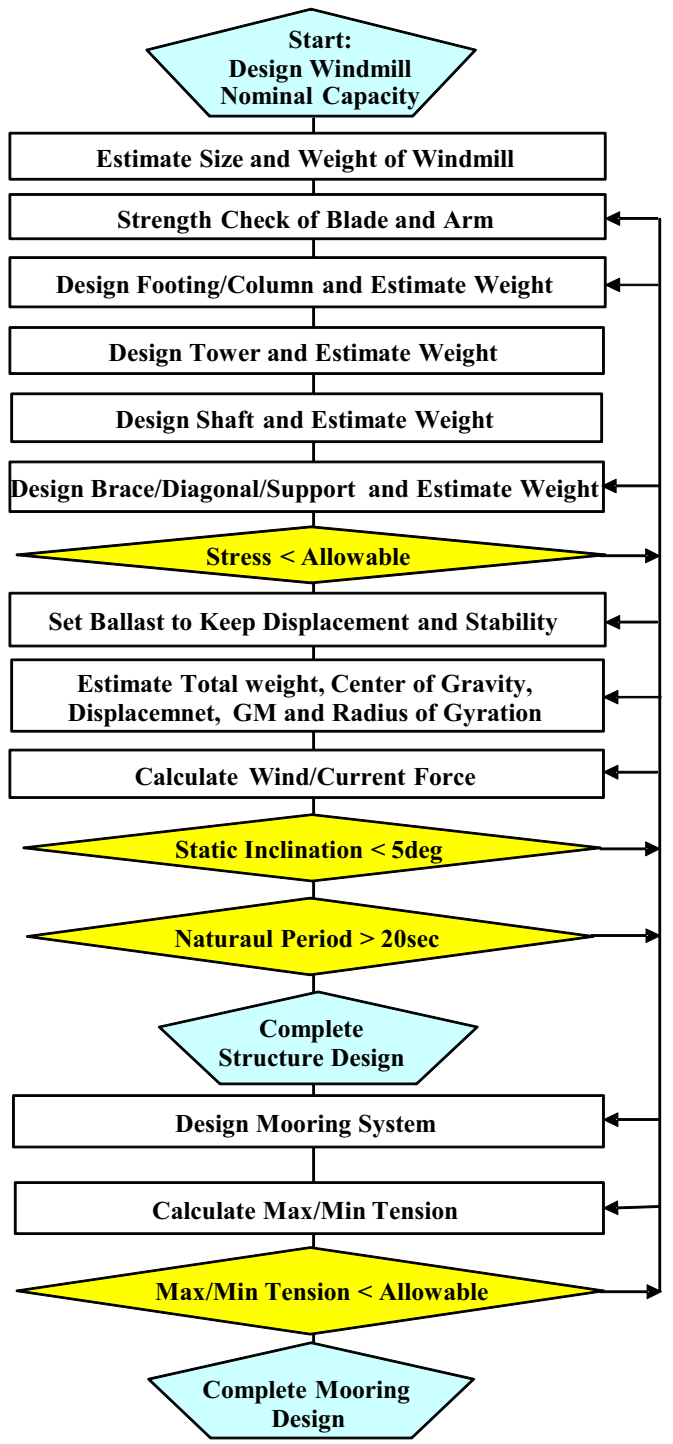

Fig. 4 Design procedure

oped program. (Most of the specifications described below in Sect. 3.1 are based on Kobayashi et al. (1985)).

\subsection{Specifications of the developed computer code}

\section{Equations of motions}

In principle, the equations of motions that describe the response time history should be expressed with convolution integral accounting for the memory effect (Cummins 1962). However, in the present computations, for the sake of simplicity, it is assumed that the equations of motions can be expressed by the following equation, in which hydrodynamic coefficients $\left(A_{i j}, N_{i j}\right)$ at a certain representative period are taken.(As for the representative period, for example, the average period of the corresponding wave spectrum may be taken.)

$$
\begin{aligned}
& \sum_{j=1}^{6}\left\{\left(M_{i j}+A_{i j}\right) \ddot{x}_{j}+N_{i j} \dot{x}_{j}+k_{i j} x_{j}\right\} \\
& =D_{i}+T_{i}+F_{\text {wave }_{i}}+F_{\text {drift }_{i}}+F_{\text {wind }_{i}} \\
& \quad+F_{\text {current }_{i}}+F_{w_{i}}
\end{aligned}
$$

here $i=1 \sim 6$, and

$x_{j}$ :motion displacement in $j$ th direction,

$M_{i j}$ :mass in $i$ th motion $(i=1 \sim 3)$, mass moment of inertia in $i$ th motions $(i=4 \sim 6)$,

$$
\left(M_{11}=M_{22}=M_{33}, M_{i j}=0 \text { if } i \neq j\right) .
$$

$A_{i j}$ : added mass in $i$ th motion due to $j$ th motions,

$N_{i j}$ : damping coefficient in $i$ th motion due to $j$ th motion,

$k_{i j}$ : restoring force/moment coefficient in $i$ th motion due to $j$ th motion,

$D_{i}$ : viscous drag force/moment in $i$ th direction,

$T_{i}$ : mooring force/moment in $i$ th direction,

$F_{\text {wave }_{i}}$ : wave force/moment in $i$ th direction,

$F_{\text {drift }_{i}}:$ drift force/moment in $i$ th direction,

$F_{\text {wind }_{i}}$ : wind force/moment in $i$ th direction,

$F_{\text {current }_{i}}:$ current force/moment in $i$ th direction, and $F_{\mathrm{wt}_{i}}$ : force/moment due to the gyroscopic moment of the wind turbine in $i$ th direction.

2. Viscous drag force

The drag force proportional to the square of the velocity of a water particle relative to the corresponding floating structure can be taken into account. When viscous drag forces are taken into account, since it is nonlinear with respect to wave amplitude, iterative calculations are necessary until convergent solutions are obtained. The expected Reynolds number and $\mathrm{KC}$ number are $10^{5}$ (brace) $\sim 10^{6}$ (column) and 1 (column) $\sim 10$ (brace) respectively. Accordingly, referring to standard textbooks (e.g., Hoerner 1965), the drag coefficient, $C_{\mathrm{D}}=1.17$ and $C_{\mathrm{D}}=0.83$ were used for the direction perpendicular to the central axis of a cylindrical structure and for the direction perpendicular to the bottom surface of a cylindrical structure, respectively.

\section{Mooring force/moment}

Mooring forces are evaluated simply by multiplying the linear restoring coefficient (spring constant) and the displacement. The dynamic effect due to the motions of mooring lines is not accounted for.

4. Wave force/moment

Supposing the power spectrum of irregular waves is $S(\omega)$, then the surface displacement $\zeta(t)$ is expressed as follows.

$\zeta(t)=\sum_{i=1}^{N} \zeta_{i} \cos \left(k_{i} x \cos \chi+k_{i} y \sin \chi-\omega_{i} t-\varepsilon_{i}\right)$,

where $\zeta_{i}=\sqrt{2 S\left(\omega_{i}\right) \Delta \omega_{i}}$, and 
Table 2 Particulars of the designed semi-submersibles
Table 3 Values of relevant parameters of the designed semi-submersibles

\begin{tabular}{|c|c|c|c|}
\hline & & $\begin{array}{l}\text { 3-Column } \\
\text { semi-submersible }\end{array}$ & $\begin{array}{l}\text { 4-Column } \\
\text { semi-submersible }\end{array}$ \\
\hline \multicolumn{2}{|l|}{ Number of columns } & 3 & 4 \\
\hline \multicolumn{2}{|c|}{ Total mass (kg) (ballast mass (kg)) } & $6.69 \times 10^{6}\left(3.57 \times 10^{6}\right)$ & $1.12 \times 10^{7}\left(0.48 \times 10^{7}\right)$ \\
\hline \multicolumn{2}{|l|}{ Displacement $\left(\mathrm{m}^{3}\right)$} & 6,692 & 11,184 \\
\hline \multicolumn{2}{|c|}{ Center-to-center distance between columns (m) } & 93.0 & 130.0 \\
\hline \multicolumn{2}{|l|}{ Draft (m) } & 15.0 & 18.5 \\
\hline \multirow[t]{2}{*}{ Column } & Diameter (m) & 6.8 & 5.4 \\
\hline & Depth (m) & 20.0 & 30.0 \\
\hline \multirow[t]{2}{*}{ Footing } & Diameter (m) & 27.0 & 21.0 \\
\hline & Depth (m) & 2.0 & 4.0 \\
\hline \multicolumn{2}{|l|}{$I_{\mathrm{xx}}\left(\mathrm{kg} \mathrm{m}^{2}\right)$} & $1.28 \times 10^{10}$ & $2.22 \times 10^{10}$ \\
\hline \multicolumn{2}{|l|}{$I_{\mathrm{yy}}\left(\mathrm{kg} \mathrm{m}^{2}\right)$} & $1.28 \times 10^{10}$ & $2.22 \times 10^{10}$ \\
\hline \multicolumn{2}{|l|}{$I_{\mathrm{zz}}\left(\mathrm{kg} \mathrm{m}^{2}\right)$} & $1.82 \times 10^{10}$ & $3.39 \times 10^{10}$ \\
\hline \multicolumn{2}{|l|}{$\mathrm{GM}(\mathrm{m})$} & 16.0 & 6.3 \\
\hline \multicolumn{2}{|l|}{$\mathrm{KG}(\mathrm{m})$} & 14.5 & 18.8 \\
\hline \multirow{12}{*}{$\begin{array}{l}\text { Mooring line spring } \\
\text { constant }\end{array}$} & $k_{11}(\mathrm{~N} / \mathrm{m})$ & $5.5 \times 10^{5}$ & $8.2 \times 10^{5}$ \\
\hline & & $3.7 \times 10^{4}$ & $2.0 \times 10^{4}$ \\
\hline & $k_{22}(\mathrm{~N} / \mathrm{m})$ & $4.7 \times 10^{5}$ & $7.9 \times 10^{5}$ \\
\hline & & $3.7 \times 10^{4}$ & $2.0 \times 10^{4}$ \\
\hline & $k_{33}(\mathrm{~N} / \mathrm{m})$ & $4.5 \times 10^{5}$ & $5.9 \times 10^{5}$ \\
\hline & & $7.8 \times 10^{3}$ & $2.9 \times 10^{4}$ \\
\hline & $k_{44}(\mathrm{~N}-\mathrm{m} / \mathrm{rad})$ & $6.5 \times 10^{8}$ & $1.6 \times 10^{9}$ \\
\hline & & $2.3 \times 10^{7}$ & $8.3 \times 10^{7}$ \\
\hline & $k_{55}(\mathrm{~N}-\mathrm{m} / \mathrm{rad})$ & $6.5 \times 10^{8}$ & $1.6 \times 10^{9}$ \\
\hline & & $2.3 \times 10^{7}$ & $8.3 \times 10^{7}$ \\
\hline & $k_{66}(\mathrm{~N}-\mathrm{m} / \mathrm{rad})$ & $1.8 \times 10^{7}$ & $3.4 \times 10^{7}$ \\
\hline & & $2.0 \times 10^{6}$ & $2.3 \times 10^{6}$ \\
\hline
\end{tabular}

* Mooring line spring constant (upper level: polyester taut lines, lower level: steel chain catenary lines)

\begin{tabular}{|c|c|c|c|c|}
\hline & & $\begin{array}{l}\text { 3-Column } \\
\text { semi-sub }\end{array}$ & $\begin{array}{l}\text { 4-Column } \\
\text { semi-sub }\end{array}$ & $\begin{array}{l}\text { Allowable } \\
\text { limit }\end{array}$ \\
\hline Max wave height (m) & & 25.0 & 25.0 & \\
\hline Max wind velocity $(\mathrm{m} / \mathrm{s})$ & & 50.0 & 50.0 & \\
\hline \multirow{4}{*}{$\begin{array}{l}\text { Natural period (sec) } \\
\text { (taut polyester } \\
\text { mooring) }\end{array}$} & Surge/sway & 31 & 32 & $>30$ \\
\hline & Heave & 26 & 25 & $>30$ \\
\hline & Roll/pitch & 30 & 30 & $>30$ \\
\hline & Yaw & 262 & 311 & $>30$ \\
\hline Static inclination (deg.) & & 0.9 & 5.0 & $<5.0$ \\
\hline \multirow[t]{3}{*}{ Bending stress (MPa) } & Brace & $14.6 \times 10^{5}$ & $3.32 \times 10^{5}$ & $<3.33 \times 10^{5}$ \\
\hline & Shaft & $1.85 \times 10^{5}$ & $3.13 \times 10^{5}$ & $<3.33 \times 10^{5}$ \\
\hline & Arm & $0.62 \times 10^{5}$ & $1.87 \times 10^{5}$ & $<2.71 \times 10^{5}$ \\
\hline \multirow{2}{*}{$\begin{array}{l}\text { Max mooring tension } \\
(\mathrm{N})(\text { static + dynamic) }\end{array}$} & Catenary steel chain & $0.20 \times 10^{6}$ & $1.77 \times 10^{6}$ & $<4.82 \times 10^{6}$ \\
\hline & Taut polyester & $3.97 \times 10^{6}$ & $5.10 \times 10^{6}$ & $<11.3 \times 10^{6}$ \\
\hline
\end{tabular}


$\omega_{i}$ : radial frequency of $i$ th component wave,

$k_{i}$ : wave number,

$\varepsilon_{i}$ : random numbers that distributes uniformly between

$0 \sim 2 \pi$,

$\chi$ : wave direction,

$\Delta \omega_{i}$ : division width of radial frequency.

In waves described by Eq. (2), wave force or moment

$F_{w}(t)$ is written as follows.

$F_{w}(t)=\sum_{i=1}^{N} H_{w}\left(\omega_{i}\right) \cdot \zeta_{i} \cos \left(\omega_{i} t+\varepsilon_{w}\left(\omega_{i}\right)+\varepsilon_{i}\right)$.

Here, $H_{w}(\omega), \varepsilon_{w}(\omega)$ represent respectively the force/moment amplitude and the phase in regular waves of frequency $\omega$ and unit amplitude.

5. Drift force/moment

In order to obtain the time-varying drift force/moment in irregular waves, in principle, velocity potentials up to $2 \mathrm{nd}$ order are needed to be calculated. In this analysis, however, for the sake of simplicity, they are calculated in an approximate manner by using the method proposed by (Pinkster (1974)) as follows.

$$
\begin{aligned}
F_{D}(t)= & \sum_{i=1}^{N} \sum_{j=1}^{N} H_{D}\left(\frac{\omega_{i}+\omega_{j}}{2}\right) \zeta_{i} \zeta_{j} \\
& \cos \left\{\left(\omega_{i}-\omega_{j}\right) t+\varepsilon_{i}-\varepsilon_{j}\right\} .
\end{aligned}
$$

Here $H_{D}(\omega)$ represents the response function of steady drift force/moment in regular waves of frequency $\omega$ and unit amplitude.

6. Wind and current force/moment

Wind and current force/moment are calculated by the following equations

$F(t)=\frac{1}{2} \rho \mathrm{SC}_{D} v(t)^{2}$

Here, $\rho, S, C_{D}, v(t)$ are the density of air/water, projected area, drag coefficient, wind/current speed relative to the structure, respectively.

As is evident in Eq. (5), the wind turbine load on the rotor blades was simplified by only accounting for a drag coefficient. The method applied in the present study is aimed to roughly evaluate the effect of drag force acting on a wind turbine as a whole on the dynamics of the supporting floating structure. Elaborate evaluation of the aerodynamic loads and their effect on the supporting structure is not within the scope of the present study.

7. Moment induced by the gyroscopic moment due to rotating blades
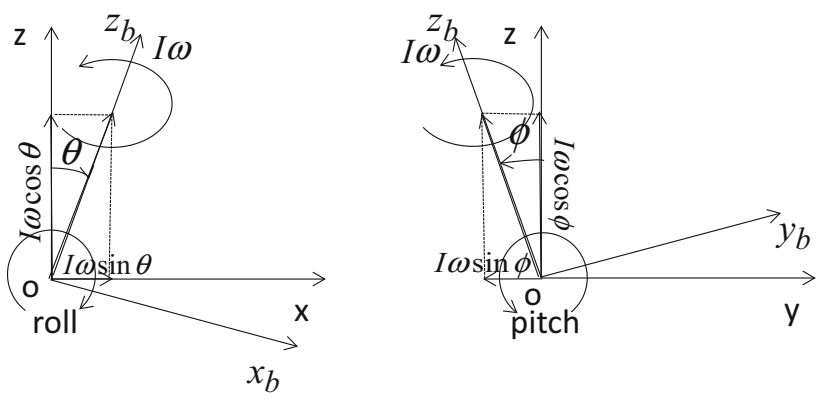

Fig. 5 Moment due to the gyroscopic moment caused by the rotation of blades

First, consider a space-fixed coordinate system $(x, y, z)$, in which the $x-y$ plane coincides with the horizontal plane while the $z$ axis is vertically upward. The origin o of the coordinate system is placed at the root of the SWVAWT. Next, also consider a body (supporting floating structure)fixed coordinate system $\left(x_{b}, y_{b}, z_{b}\right)$, which coincides with the $(x, y, z)$ coordinate system when the body is at rest. (see Fig. 5)

As shown in Fig. 5, the blades are assumed to be rotating about $z_{b}$ axis with angular velocity $\omega$. The angular momentum of the rotating blades of the SWVAWT is directed along the $z_{b}$ axis with its magnitude $I \omega$, where $I$ represents the mass moment of inertia of the rotating blades around the $z_{b}$ axis.

(i) Effect of time-wise variation of $\omega$ As the effect of time-wise variation of $\omega$, yaw moment $I \dot{\omega}$ around $z$ axis is induced.

(ii) Effect of pitch $\theta$

Under the pitch motion $\theta$, the $x$ component of the angular momentum is $I \omega \sin \theta$, and its time derivative is

$$
\frac{\mathrm{d}}{\mathrm{d} t}(I \omega \sin \theta)=I \dot{\omega} \sin \theta+I \omega \dot{\theta} \cos \theta \approx I \dot{\omega} \theta+I \omega \dot{\theta} .
$$

Thus as the result of pitch motion, roll moment $I \dot{\omega} \theta+$ $I \omega \dot{\theta}$ around $x$ axis is induced.

(iii) Effect of roll $\phi$

Under the roll motion $\phi$, the $y$ component of the angular momentum is $-I \omega \sin \phi$, and its time derivative is

$$
\begin{aligned}
\frac{\mathrm{d}}{\mathrm{d} t}(-I \omega \sin \phi) & =-I \dot{\omega} \sin \phi-I \omega \dot{\phi} \cos \phi \\
& \approx-I \dot{\omega} \phi-I \omega \dot{\phi} .
\end{aligned}
$$

Thus, as the result of roll motion, pitch moment $-(I \dot{\omega} \phi+I \omega \dot{\phi})$ around $y$ axis is induced. 
After all, the effect of a SWVAWT on the motions of the floating structure is summarized as follows.

Moment about $x$ axis: $I \dot{\omega} \theta+I \omega \dot{\theta}$,

Moment about $y$ axis: $-(I \dot{\omega} \phi+I \omega \dot{\phi})$, and Moment about $z$ axis: $I \dot{\omega}$.

These moments correspond to $F_{w t_{i}}$ in the equations of motions (Eq. (1)).

8. Numerical integration

For the numerical integration of Eq. (1), the Newmark- $\beta$ method $(\beta=1 / 6)$ was used.

\subsection{Validation of the developed computer code}

As a part of the validation of the developed computer code, calculations were carried out for the following cases.

1. RAO (Response Amplitude Operator) of a single vertical truncated cylinder.

The particulars of the cylinder are summarized in Table 4. In Fig. 6, RAOs of heave and pitch obtained by frequencydomain calculations and those obtained by time-domain calculations are compared. The agreements are quite good.

2. Time histories of surge and heave motions of a 4-column semi-submersible.

Table 4 Particulars of the truncated vertical cylinder subjected to the validation of the developed computer code

\begin{tabular}{ll}
\hline Mass & $785.4 \mathrm{~kg}$ \\
Diameter & $1.0 \mathrm{~m}$ \\
Draft & $1.0 \mathrm{~m}$ \\
$\mathrm{GM}$ & $0.625 \mathrm{~m}$ \\
Center of gravity & $0.5 \mathrm{~m}$ below the free surface \\
Mass moment of inertia & $I_{\mathrm{xx}}=I_{\mathrm{yy}}=I_{\mathrm{zz}}=49.1 \mathrm{~kg} \mathrm{~m}^{2}$ \\
Water depth & $2.0 \mathrm{~m}$
\end{tabular}

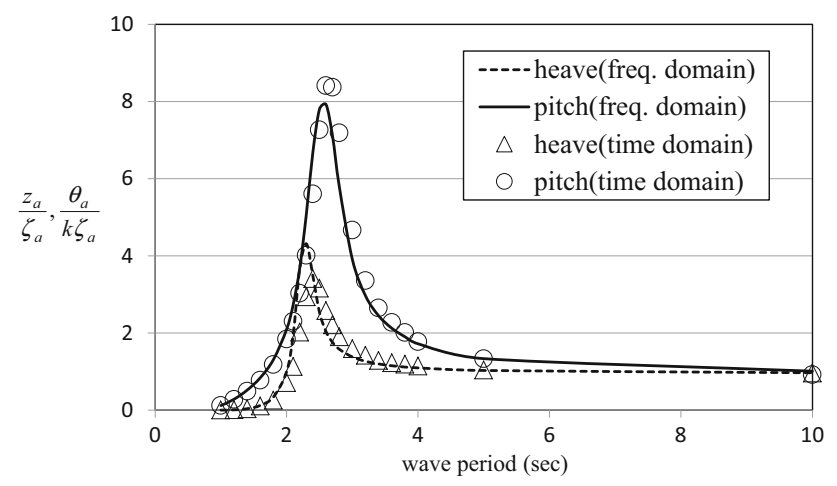

Fig. 6 Comparison of RAOs obtained by frequency-domain calculations and those obtained by time-domain calculations
In Figs. 7 and 8, time histories of surge and heave motions in irregular waves obtained by the superposition of frequency-domain responses and those obtained by the direct time-domain calculations in the same time series of waves are compared. The agreements are again quite good.

\section{Case study of power supply to offshore Greek islands}

Wind energy has always contributed to Greece's energy needs and will play a significant role in further investments since Greece, as any EU country member, sets the same energy targets for the year 2020, which includes meeting the $20 \%$ of the primary energy demand by renewable energy sources. The focus on wind energy is being supported by Greece's noteworthy wind energy potential, as well as an exceptional offshore wind power resource prevailing in the Aegean Sea.

The case of the Aegean islands is of particular interest for numerous reasons. More and more studies prove the rich offshore wind potential that continues even during the peak-load summer periods while at the same time, the islands display an annual increase of the electricity consumption at a rate of $8 \%$, almost double the mainland rate (Hatziargyriou et al. 2006). Due to geographic, technical, financial, and social reasons, their interconnection to the mainland grid still remains under planning. Hence, they base their electricity supply on, usually non-financially viable, small autonomous power stations. Offshore wind development can offer an efficient way to cover the country's medium and longer term electricity supply, ensure the security of this supply and contribute to the protection of the environment from climate change. Moreover it will be a great contribution to enhancing the competitiveness of the economy by exploiting a significant indigenous energy source and promoting better integration of the islands into the country's energy system.

\subsection{Wave and wind statistics of offshore Greece}

Positioning an offshore wind farm is a decision based upon a combination of parameters with the main point being that of having a good wind potential. Based on previous research (Katsoulis 1993), the highest winds can be found in the central Aegean Sea. Islands that belong to the NE Cyclades complex, show a remarkable offshore environment. The bathymetry of the area introduces water depths of $50 \mathrm{~m}$ and more at only a few $\mathrm{km}$ offshore from the islands. This is a fact that makes clear that an economically viable offshore development would come from floating wind systems.

The description of the sea and wind state of the central Aegean Sea was based on a statistical analysis performed with a set of data including wave, current, and wind con- 
Fig. 7 Comparison of the time history of surge response obtained by superposition of frequency-domain responses and that obtained by direct time-domain calculation. a Superposition of frequency domain responses. b Direct time domain calculations

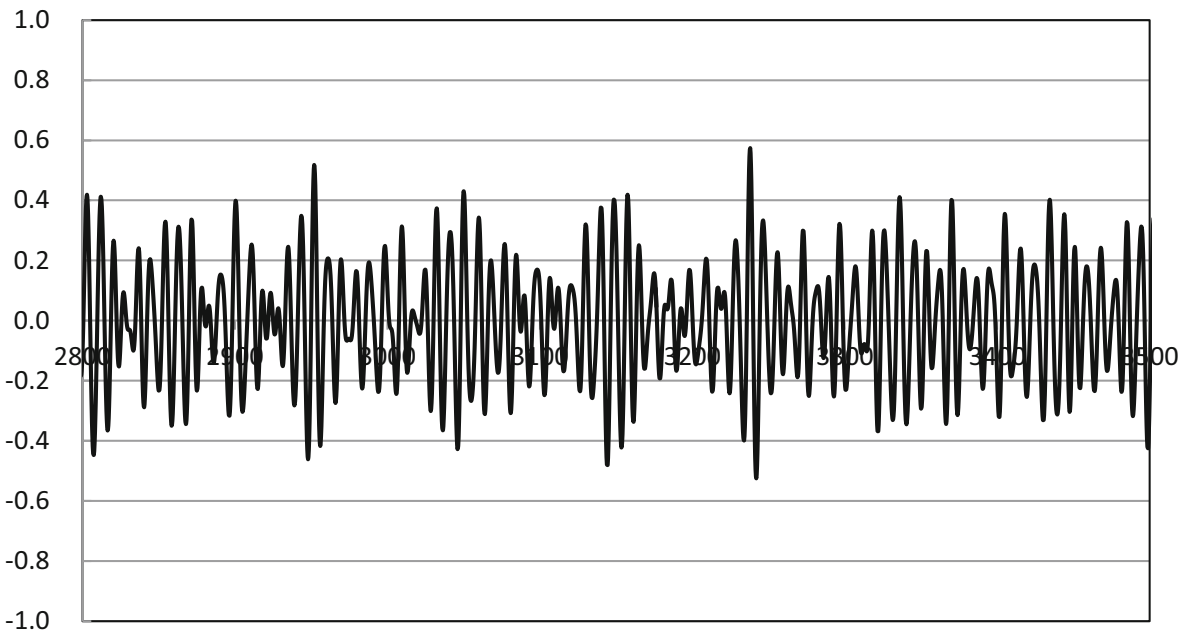

(a) Superposition of frequency domain responses

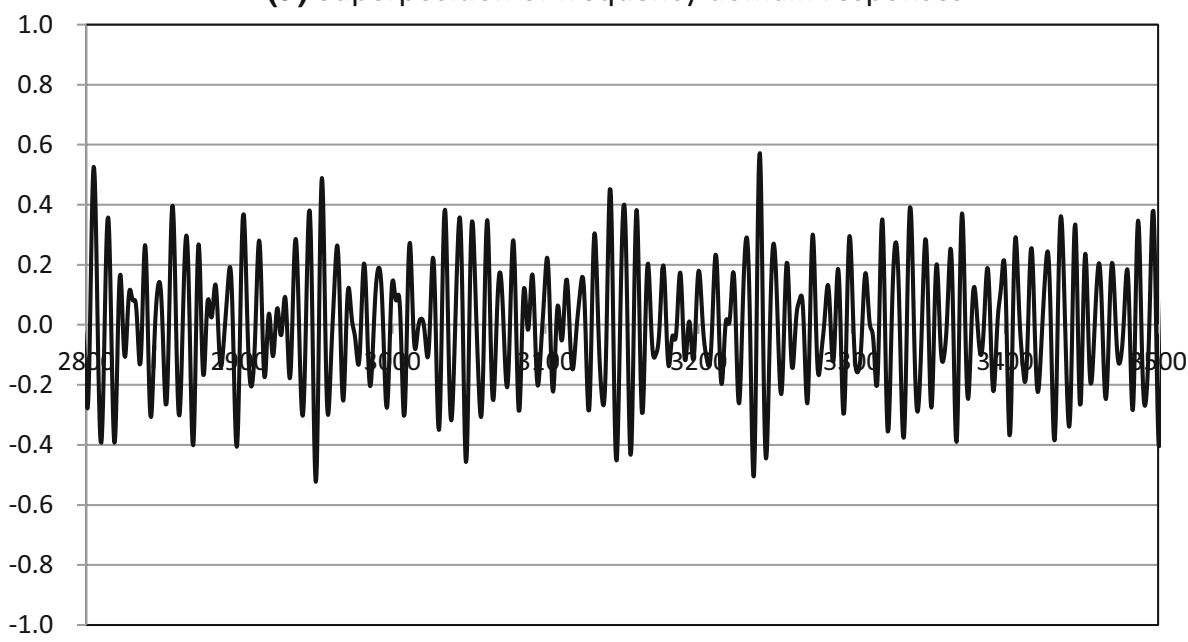

(b) Direct time domain calculations ditions that were provided by the POSEIDON system of the Hellenic Center for Marine Research. From the POSEIDON network of observation buoys, the buoy station named "Mykonos", placed East of Mykonos Island and North of Naxos Island was selected as a representative point of the central Aegean Sea. Good quality measurements were available for a total of 11 years, 2001-2012, and were analyzed statistically for defining the sea state of the area and acquiring the needed information such as significant wave heights, average wave periods, wind speeds, etc. (POSEIDON Operational Oceanography System 2013).

\subsubsection{Wave}

The wave spectrum $S(\omega)$ for the area of interest can be determined from measured wave elevation records through several mathematical formulations. In this case, an appropriate description for the spectrum is selected to be JONSWAP spectra (Joint North Sea Wave Project). The two important parameters are the significant wave height $\mathrm{H} 1 / 3$, which is defined as the mean of the highest $1 / 3$ of waves and the average wave period $T_{1}$. Using the available values for the significant wave height and average wave period, the spectrum was determined by using the equation below and a selection of frequencies within the spectrum range defined was made:

$S(\omega)=\frac{155 H_{1 / 3}^{2}}{T_{1}^{4} \omega^{5}} \exp \left(\frac{-944}{T_{1}^{4} \omega^{4}}\right)(3.3)^{Y}$,

where

$Y=\exp \left\{-\left(\frac{0.19 \omega T_{1}-1}{\sqrt{2} \sigma}\right)^{2}\right\}$

and,

$\sigma= \begin{cases}0.07 & \text { if } \omega \leq 5.24 / T_{1} \\ 0.09 & \text { if } \omega>5.24 / T_{1}\end{cases}$ 
Fig. 8 Comparison of the time history of heave response obtained by superposition of frequency-domain responses and that obtained by direct time-domain calculation. a Superposition of frequency domain responses. b Direct time domain calculations

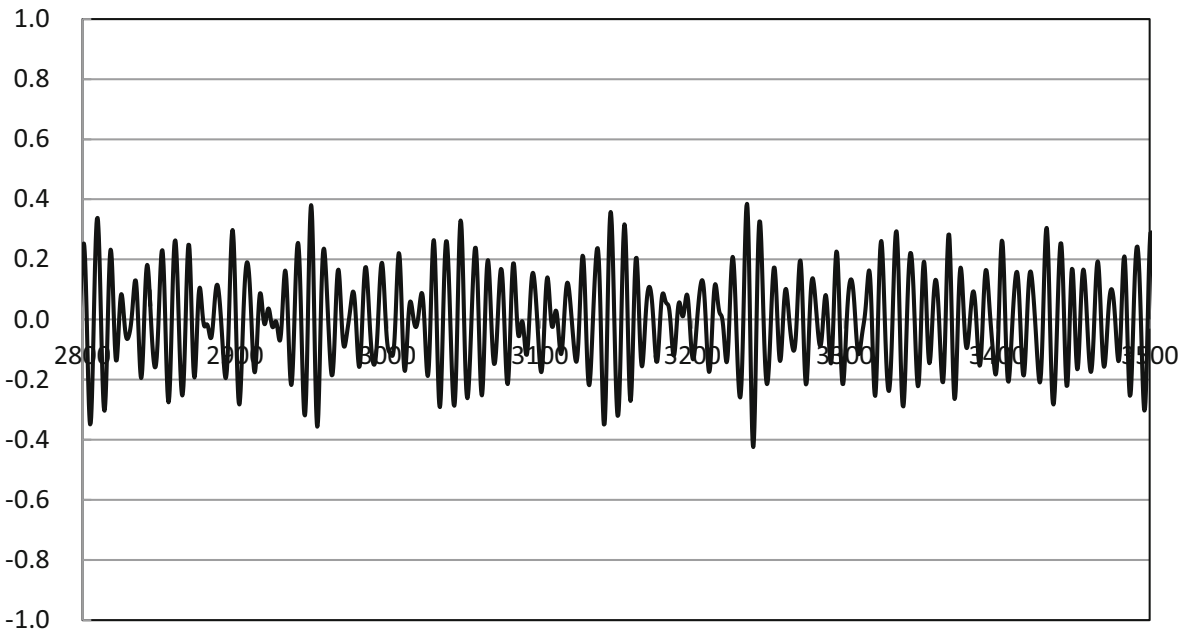

(a) Superposition of frequency domain responses

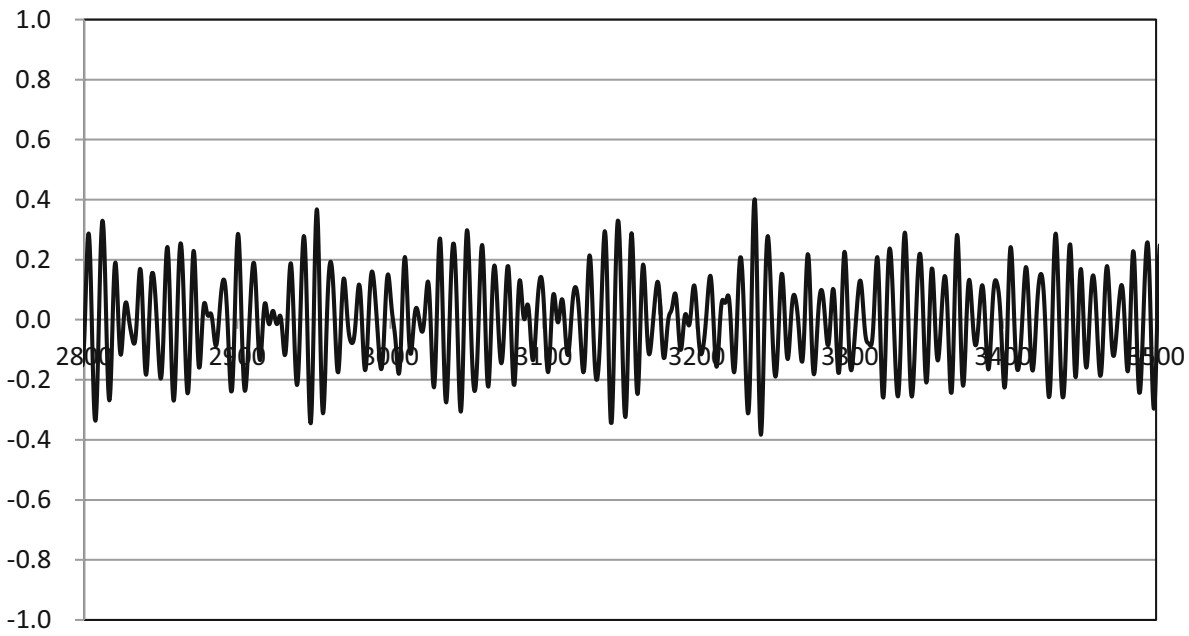

(b) Direct time domain calculations

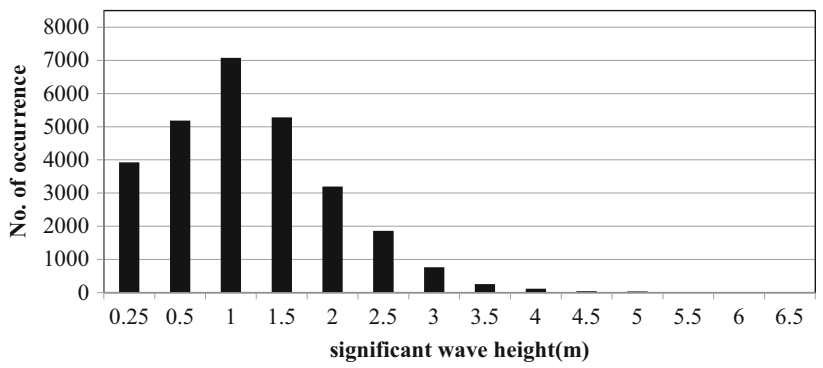

Fig. 9 Significant wave height occurrence over 11 years at offshore Greece

life of the system, an extrapolation of the data is necessary. The probability of an extreme wave happening in the next years is found by dividing the average wave period of the 2001-2012 data, which was calculated at $3.68 \mathrm{sec}$, by the life expectancy of the system which was chosen at 20 years. The Weibull distribution was used for providing the best fit described by the formula for the cumulative distribution function as: 


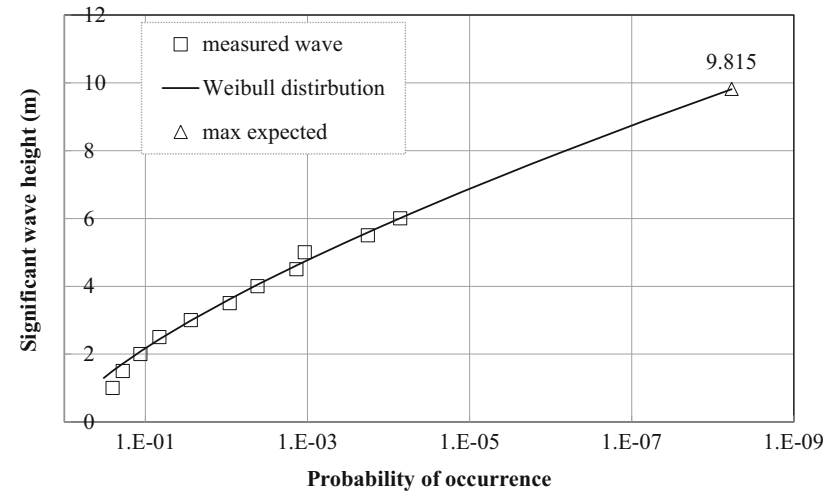

Fig. 10 Maximum expected significant wave height occurrence in 20 years at offshore Greece

$F(x ; k, \lambda)=1-e^{-(x / \lambda)^{k}}$ for $x \geq 0$ and $k, \lambda>0$.

The occurrence of the survival condition was found at a probability equal to $5.83 \times \mathrm{E}-09$, resulting in a maximum expected significant wave height at the value of $9.82 \mathrm{~m}$, as shown in Fig. 10.

For predicting the average wave period of the significant waves $T_{1} / 3$, Wilson's prediction formula was used (Goda 2002), that is:

$T_{1 / 3}=3.3 \times\left(H_{1 / 3}\right)^{0.63}$

assuming that the period and the wave height are expressed in second and in meter respectively. Then the average period of all the waves $T_{1}$ was estimated while assuming that the following relationship holds.

$T_{1}=T_{1 / 3} / 1.1$

Substituting the maximum expected significant wave height $9.82 \mathrm{~m}$ into Eq. (11) and using Eq. (12), the average wave period of the severest expected sea state that a floating wind turbine may encounter during its life expectancy, that is 20 years, at offshore Greece is obtained as $T_{1}=12.64 \mathrm{sec}$.

As for a representative sea state for an operational condition of a floating wind turbine at offshore Greece, again referring to the measured data over 11 years, the significant wave height $\mathrm{H} 1 / 3$ and the average wave period $T_{1}$ were set to be as $H_{1 / 3}=2.75 \mathrm{~m}$ and $T_{1}=5.06 \mathrm{sec}$, respectively.

\subsubsection{Wind}

From the available data for the wind speeds over the 11 years of study, variations in seasonal or monthly average wind speeds were noticed, that is, high occurrence of average wind speeds more than $10 \mathrm{~m} / \mathrm{s}$ during the months July-September, as well as February-March with average values more than $7.5 \mathrm{~m} / \mathrm{s}$. In general, in every month, the appearance of the

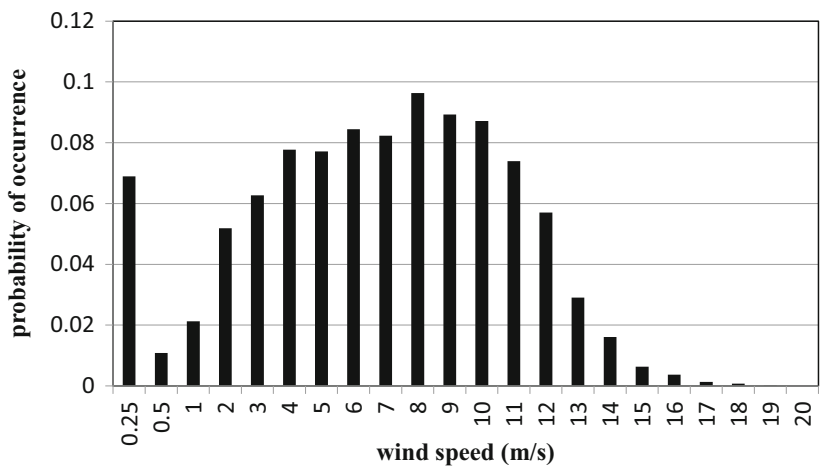

Fig. 11 Wind speeds occurrence over 11 years, 2001-2012, at offshore Greece

Table 5 Representative sea states at offshore Greece

\begin{tabular}{llll}
\hline & $\begin{array}{l}\text { Significant } \\
\text { wave height } \\
(\mathrm{m})\end{array}$ & $\begin{array}{l}\text { Average } \\
\text { wave period } \\
(\mathrm{sec})\end{array}$ & $\begin{array}{l}\text { Wind speed } \\
(\mathrm{m} / \mathrm{s})\end{array}$ \\
\hline Maximum sea state & 9.82 & 12.64 & 40 \\
Medium sea state & 2.75 & 5.06 & 12 \\
\hline
\end{tabular}

monthly highest wind speed values was observed on average about $50 \%$ of the days of each respective month. North wind direction was found dominant while there were significant occurrences of NW and SW directions. As it is shown in Fig. 11, in the figure of wind distribution for the total data, the wind speeds with highest occurrence are in the range of $6-10 \mathrm{~m} / \mathrm{s}$, while there was a large number of very low wind speeds below $0.25 \mathrm{~m} / \mathrm{s}$.

\subsubsection{Representative sea states at offshore Greece}

Thus, from the measured data of waves and wind, the sea states shown in Table 5 were chosen as representative sea states at offshore Greece.

\subsection{Dynamic response analyses of floating wind turbines}

Dynamic response analyses of the 3-column and the 4column semi-submersible SWVAWTs were carried out using the computer code described in Sect. 3. In all the analyses, head wave and wind shown in Fig. 12 were assumed. Current was not taken into account. The water depth was assumed to be $100 \mathrm{~m}$.

The effect of turbulent wind on the dynamic response of floating wind turbines was not taken into account, because as mentioned in 3.1 (6), elaborate evaluation of aerodynamic loads on wind turbines is not within the scope of the present study. It is also noted that, since frequencies of most of the aerodynamic loads induced by turbulent wind are far higher than the natural frequencies of the dynamic responses of the 
floating structure, the effect of turbulent wind on the dynamics of the floating structure can be considered to be negligible.

\subsubsection{RAO (Response Amplitude Operator)}

As one of the basic dynamic response characteristics of floating wind turbines, RAOs (Response Amplitude Operators)

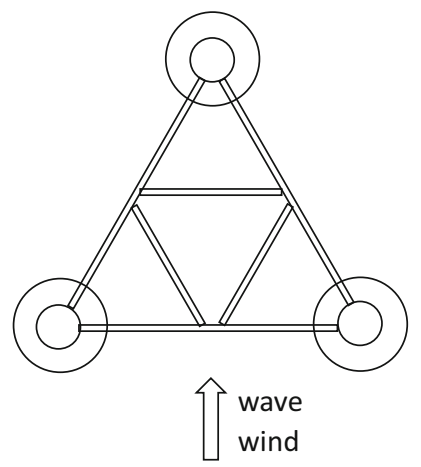

Fig. 12 A floating wind turbine in head wave and wind

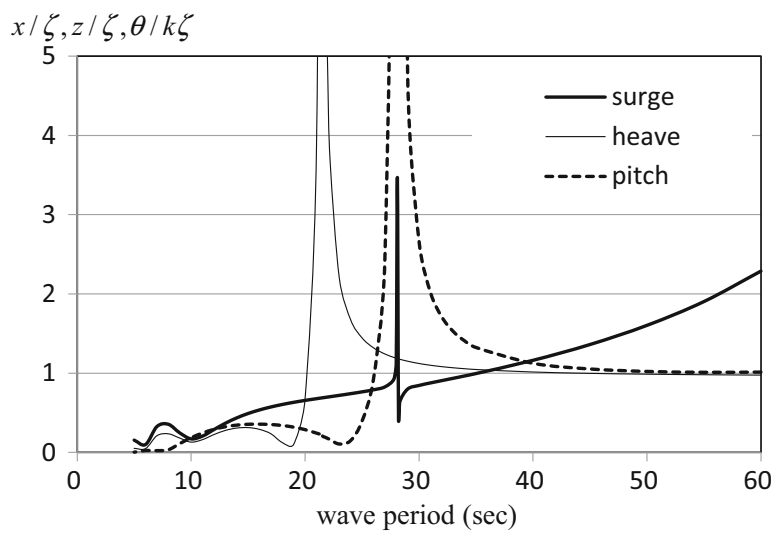

(a) catenary mooring were calculated. The floating wind turbines subjected to the calculations were the SWVAWT supported on a 3-column semi-submersible (Fig. 2) and that supported on a 4-column semi-submersible (Fig. 3). As for the mooring systems, both a steel-chain catenary mooring system and a polyester taut mooring system were examined.

Figures 13 and 14 show respectively the RAOs of the 3column supported SWVAWT and the 4-column supported SWVAWT. (In obtaining these results, in order to identify where natural periods are located, viscous damping forces were not accounted for.) One of the important RAO characteristics is where natural periods of motions are located. It is desirable if natural periods of all the 6 modes of motions are far off the relevant wave periods consisting of the wave power spectrum representing the sea site where the floating wind turbines are to be deployed. If Figs. 13 and 14 were observed from this viewpoint, all the natural periods of the 4-column supported SWVAWT in surge, heave, and pitch motions are longer than 20 sec., which, in general, is fairly long compared to the relevant wave periods of real seas, even if it is

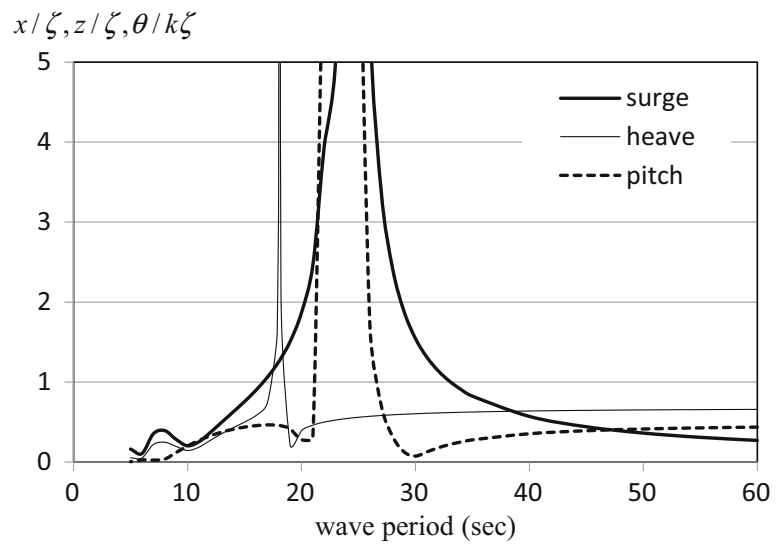

(b) taut mooring

Fig. 13 RAOs of the 3-column supported SWVAWT. a Catenary mooring. b Taut mooring

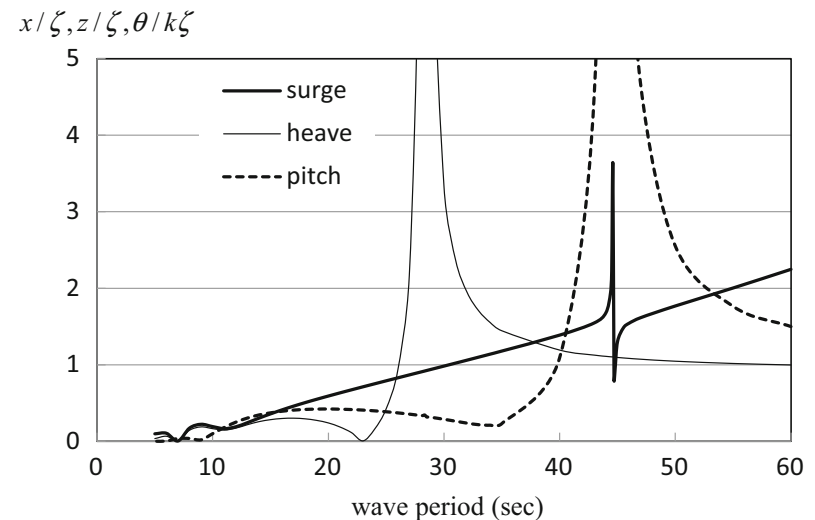

(a) catenary mooring

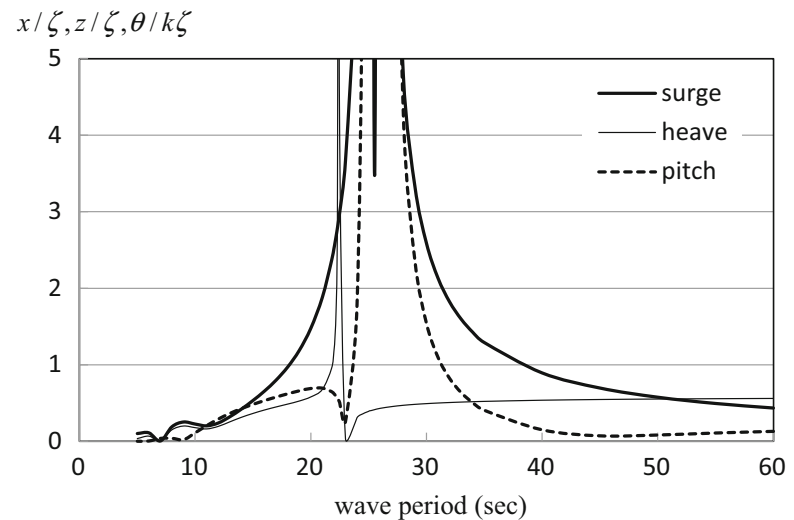

(b) taut mooring

Fig. 14 RAOs of the 4-column supported SWVAWT. a Catenary mooring. b Taut mooring 


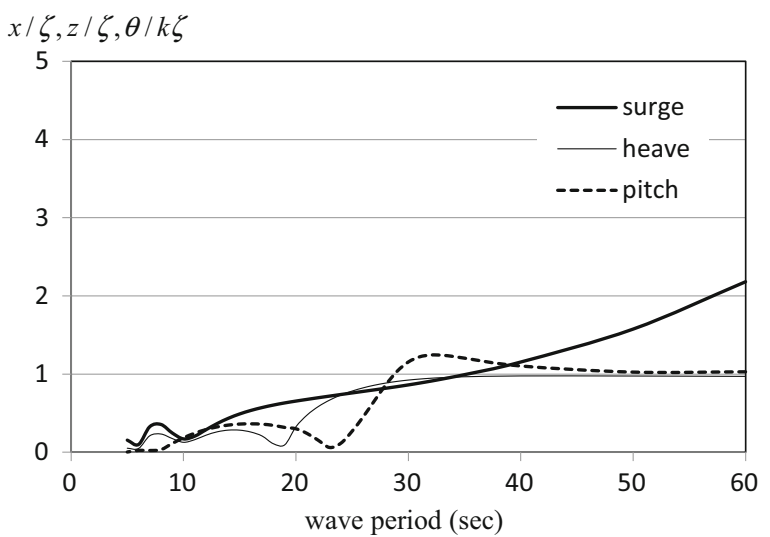

(a) catenary mooring

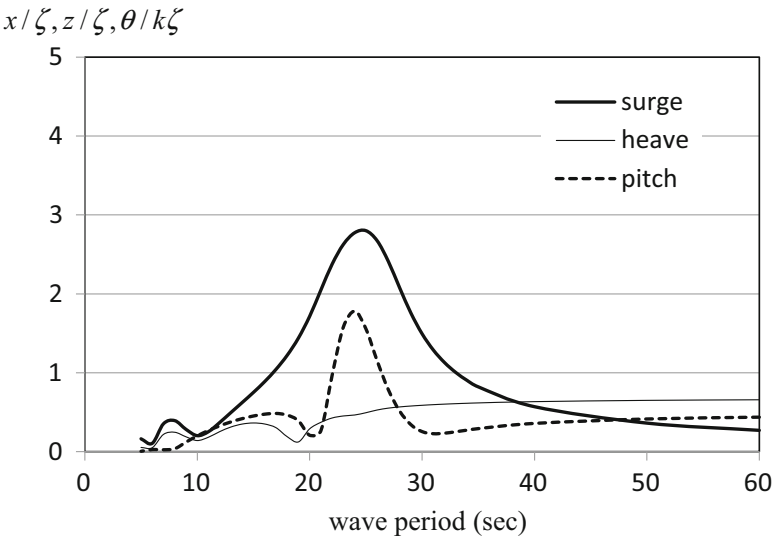

(b) taut mooring

Fig. 15 RAOs of the 3-column supported SWVAWT (with viscous drag force) (The wave height was assumed to be $9.82 \mathrm{~m}$ ). a Catenary mooring. b Taut mooring

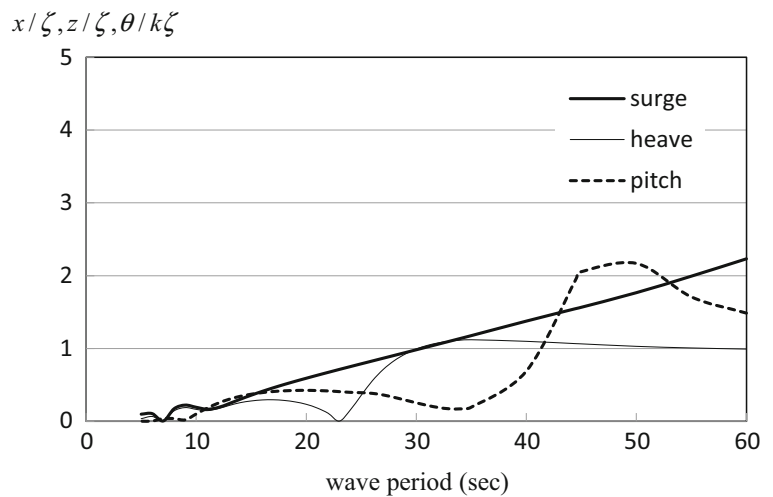

(a) catenary mooring

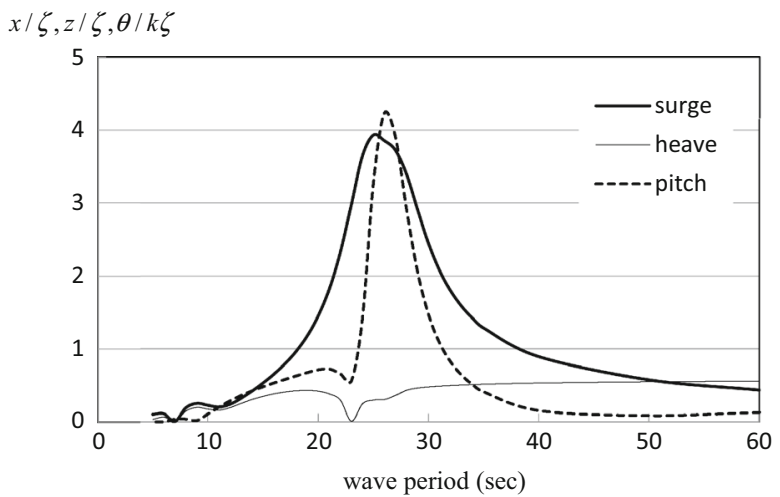

(b) taut mooring

Fig. 16 RAOs of the 4-column supported SWVAWT (with viscous drag force) (The wave height was assumed to be $9.82 \mathrm{~m}$ ). a Catenary mooring. b Taut mooring

moored by taut lines. On the other hand, the natural periods of motion of the 3-column supported SWVAWT are relatively shorter, mainly because of its lighter mass, the natural period of heave motion is even shorter than $20 \mathrm{sec}$ when moored by taut lines. The natural periods of the motions are summarized in Table 6. It is, however, shown later that motion responses are within allowable levels even in the expected severest sea state of offshore Greece.

\subsubsection{Significant and maximum values of motion amplitudes in an expected maximum sea state}

Using the calculated RAOs, significant and maximum values of motion amplitudes in an expected maximum sea state at offshore Greece, shown in Table 5, were estimated. The results are summarized in Table 7. (In obtaining the results shown in Table 7, viscous damping forces were accounted for, because, if not, it is known that the RAOs at and around natural periods become unrealistically large, which, in turn, results in unreasonably large significant and maximum values. The RAOs of the 3-column supported SWVAWT and the 4-column supported SWVAWT with viscous damping effects are shown in Figs. 15 and 16, respectively.)

As expected, the significant and maximum values are smaller when moored by steel-chain catenary mooring lines, but the significant and maximum values of the taut-moored 4-column semi-submersible can remain reasonably small, $3.0 \mathrm{~m}$ and $4.2^{\circ}$ for surge and pitch, respectively, which may be acceptable from the viewpoint of its survivability. Even those of the taut-moored 3-column semisubmersible remain $2.8 \mathrm{~m}$ and $4.1^{\circ}$, respectively, which may suggest a polyester taut mooring system could be acceptable even for a 3-column supported SWVAWT.

\subsubsection{Steady excursion and steady tilt}

In Table 8, steady excursion and steady tilt in various sea states are summarized. The values shown in the Table were 
Table 6 Natural periods identified from the calculations

\begin{tabular}{llllll}
\hline & \multicolumn{2}{l}{ 3-Column supported SWVAWT } & & \multicolumn{2}{l}{ 4-Column supported SWVAWT } \\
\cline { 2 - 3 } & Catenary mooring & Taut mooring & & Catenary mooring & Taut mooring \\
\hline Heave $(\mathrm{sec})$ & 21.5 & 18.1 & & 28.4 & 22.4 \\
Pitch $(\mathrm{sec})$ & 28.1 & 24.5 & & 44.6 & 25.1 \\
\hline
\end{tabular}

Table 7 Significant and maximum values of motions in an expected maximum sea state at offshore Greece

\begin{tabular}{|c|c|c|c|c|c|c|c|c|c|c|c|c|}
\hline & \multicolumn{6}{|c|}{ 3-Column supported SWVAWT } & \multicolumn{6}{|c|}{ 4-Column supported SWVAWT } \\
\hline & \multicolumn{3}{|c|}{ Catenary mooring } & \multicolumn{3}{|c|}{ Taut mooring } & \multicolumn{3}{|c|}{ Catenary mooring } & \multicolumn{3}{|c|}{ Taut mooring } \\
\hline & $\begin{array}{l}\text { Surge } \\
(\mathrm{m})\end{array}$ & $\begin{array}{l}\text { Heave } \\
(\mathrm{m})\end{array}$ & $\begin{array}{l}\text { Pitch } \\
\left(^{\circ}\right)\end{array}$ & $\begin{array}{l}\text { Surge } \\
(\mathrm{m})\end{array}$ & $\begin{array}{l}\text { Heave } \\
(\mathrm{m})\end{array}$ & $\begin{array}{l}\text { Pitch } \\
\left({ }^{\circ}\right)\end{array}$ & $\begin{array}{l}\text { Surge } \\
(\mathrm{m})\end{array}$ & $\begin{array}{l}\text { Heave } \\
(\mathrm{m})\end{array}$ & $\begin{array}{l}\text { Pitch } \\
\left(^{\circ}\right)\end{array}$ & $\begin{array}{l}\text { Surge } \\
(\mathrm{m})\end{array}$ & $\begin{array}{l}\text { Heave } \\
(\mathrm{m})\end{array}$ & $\begin{array}{l}\text { Pitch } \\
\left({ }^{\circ}\right)\end{array}$ \\
\hline $\begin{array}{l}1 / 3 \text { Significant } \\
\text { value }\end{array}$ & 2.3 & 1.2 & 1.7 & 4.6 & 1.4 & 2.1 & 1.8 & 1.1 & 1.6 & 3.9 & 1.5 & 2.1 \\
\hline maximum value & 4.5 & 2.5 & 3.4 & 9.1 & 2.8 & 4.1 & 3.6 & 2.3 & 3.2 & 7.8 & 3.0 & 4.2 \\
\hline
\end{tabular}

Table 8 Steady excursion and steady tilt of floating SWVAWTs

\begin{tabular}{lllll}
\hline & \multicolumn{2}{l}{$\begin{array}{l}\text { 3-Column supported SWVAWT } \\
\text { Catenary mooring }\end{array}$} & & \multicolumn{2}{l}{$\begin{array}{l}\text { 4-Column supported SWVAWT } \\
\text { Taut mooring }\end{array}$} \\
\cline { 2 - 3 } & $\begin{array}{l}\text { Steady excursion } \\
(\mathrm{m})\end{array}$ & Steady tilt $\left(^{\circ}\right)$ & & $\begin{array}{l}\text { Steady excursion } \\
(\mathrm{m})\end{array}$ \\
\hline$H_{1 / 3}=2.75 \mathrm{~m}, T_{1}=5.06 \mathrm{sec}$, wind $=12 \mathrm{~m} / \mathrm{s}$ & 4.4 & 0.4 & 0.2 & 0.9 \\
$H_{1 / 3}=2.75 \mathrm{~m}, T_{1}=5.06 \mathrm{sec}$, wind $=25 \mathrm{~m} / \mathrm{s}$ & 19.2 & 1.9 & 0.9 \\
$H_{1 / 3}=9.82 \mathrm{~m}, T_{1}=12.64 \mathrm{sec}$, wind $=40 \mathrm{~m} / \mathrm{s}$ & 54.0 & 4.8 & 2.2 & 0.9 \\
$H_{1 / 3}=9.82 \mathrm{~m}, T_{1}=12.64 \mathrm{sec}$, wind $=0 \mathrm{~m} / \mathrm{s}$ & 0.02 & 0.03 & 0.01 & 0.02 \\
\hline
\end{tabular}

obtained by taking the average values of the timeseries of the corresponding motion responses.

From Tables 7 and 8, it can be known that expected motion amplitudes are smaller if moored by catenary steel-chain lines compared to the case moored by taut polyester lines, whereas, steady excursion and steady tilt are notably larger if moored by catenary steel-chain lines compared to the case moored by taut lines. (In Table 8, steady excursion and steady tilt with no wind are shown as well, from which it can be known that steady excursion and steady tilt due to drift force is quite small.)

As for the motion amplitudes, which were shown in Table 7, even though the restoring coefficients, that is, spring constants of taut polyester mooring lines are much larger than those of catenary steel-chain mooring lines, expected motion amplitudes in practical sea states turned out to be larger if moored by taut polyester lines. The main reason for this fact may be that the natural periods of motion become shorter because of larger spring constants and, thus, become closer to relevant wave periods of the corresponding wave power spectrum. On the other hand, if moored by catenary steel-chain lines, as is evident in Table 8, steady excursion and steady tilt, especially steady excursion, are much larger than the case moored by taut polyester lines. In operational condition, steady tilt could result in reduction of power generation, while, in survival conditions, large steady tilt could endanger the floating wind turbine and large steady excursion could cause a serious problem in a wind farm, in which a large number of floating turbines are deployed with close proximity to each other.

\subsubsection{Steady yaw in wind}

One of the unique negative characteristics of a floating VAWT is the steady yaw in wind induced due to the power take-off by a wind turbine. Kanner and Yeung (2014) proposed several designs of spar-supported floating VAWTs that can reduce the yaw rotation. The steady yaw moment can be roughly estimated by dividing the power take-off with the angular velocity of the turbine.

For example, supposing a wind turbine is generating rated power $2 \mathrm{MW}$ with tip speed ratio 3.75 and rotation diameter $95.3 \mathrm{~m}$ (see Table 1) in wind $12 \mathrm{~m} / \mathrm{s}$, then the angular velocity of the wind turbine rotation $\omega$ is,

$$
\frac{95.3}{2} \times \omega / 12=3.75 \Rightarrow \omega=0.944 \mathrm{rad} / \mathrm{s}
$$


Table 9 Steady yaw angles of floating SWVAWTs in wind speed $12 \mathrm{~m} / \mathrm{s}$

\begin{tabular}{lllll}
\hline \multicolumn{2}{l}{ 3-Column supported SWVAWT } & & \multicolumn{2}{l}{ 4-Column supported SWVAWT } \\
\cline { 5 - 5 } Catenary mooring $\left(^{\circ}\right)$ & Taut mooring $\left(^{\circ}\right)$ & & Catenary mooring $\left(^{\circ}\right)$ & Taut mooring $\left(^{\circ}\right)$ \\
\hline 61.0 & 6.7 & 52.8 & 3.5 \\
\hline
\end{tabular}

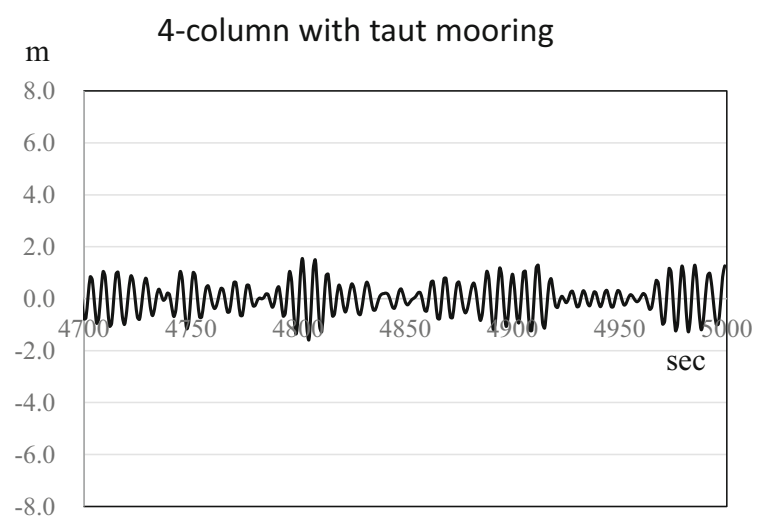

(a) wave

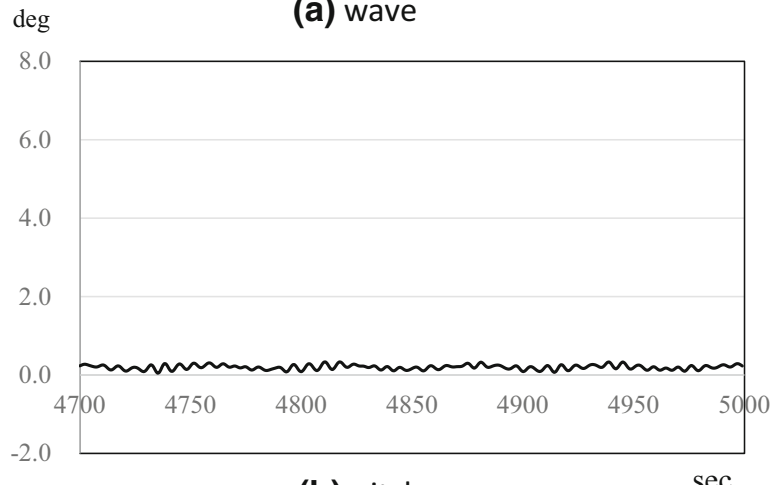

(b) pitch

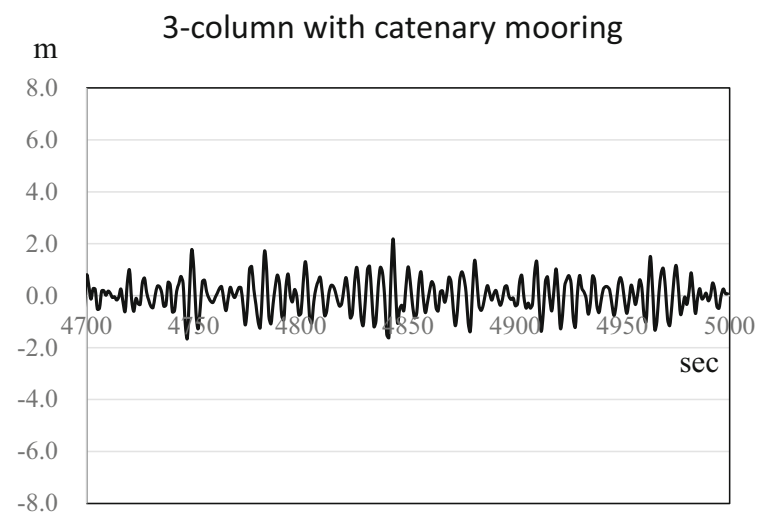

(a) wave

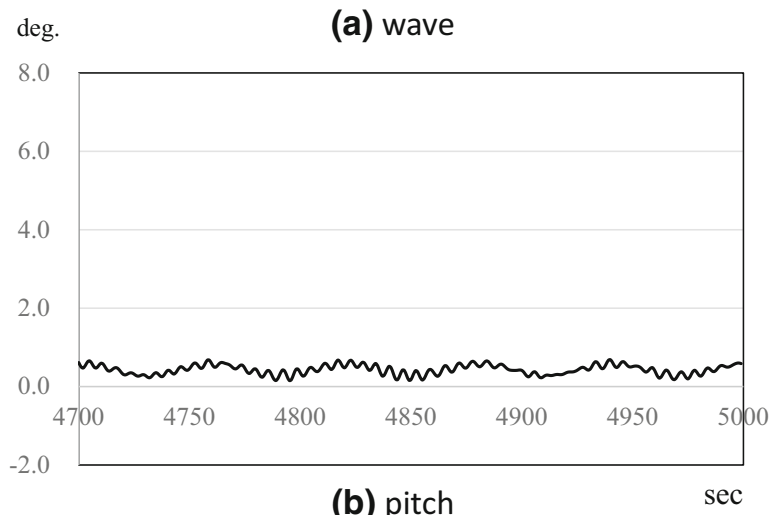

Fig. 17 Time series in expected medium sea state at offshore Greece $\left(H_{1 / 3}=2.75 \mathrm{~m}, \mathrm{~T} 0=5.06 \mathrm{sec}\right.$, wind $\left.\left(u_{w 0}\right): 12 \mathrm{~m} / \mathrm{s}\right)$. a Wave. b Pitch

Therefore, the induced yaw moment $M$ is,

$M=\frac{2 \mathrm{MW}}{\omega}=\frac{2 \times 10^{6} \mathrm{Nm} / \mathrm{s}}{0.944 \mathrm{rad} / \mathrm{s}}=2.1 \times 10^{6} \mathrm{Nm}$.

Table 9 summarizes the steady yaw angles of the 3-column supported SWVAWT and the 4-column supported SWVAWT induced by rated wind velocity $12 \mathrm{~m} / \mathrm{s}$. (As the restoring spring constants in yaw due to the mooring lines, those shown in Table 2 were used.) It is evident from the Table that excessive steady yaw angle could be induced if moored by catenary mooring lines, while, if moored by taut mooring lines, it could be kept reasonably small.

\subsubsection{Motion time series in wave and wind}

An example of a motion time series in wave and wind are calculated and shown in Figs. 17 and 18. Motions shown in
Figs. 17 and 18 are those in the medium sea state and those in the maximum sea state at offshore Greece (see Table 5), respectively.

In obtaining these results, in order to account for the possible slow variation of wind speed, wind speed $u_{w}$ was assumed to vary in the following way.

$u_{w}=u_{w 0} \cdot(1.0+0.1 \cdot \sin \omega t)$

where $u_{w 0}$ is of constant value and $\omega=2 \pi / T, T=60 \mathrm{sec}$ was assumed.

Slowly varying components of wind, or to be more specific, wind variations with periods close to the natural periods of the dynamic responses of the floating structure, especially those of horizontal dynamic responses, are important in examining the dynamic effect of wind loads on the dynamics of the floating structure, which is the reason why the wind variation of $60 \mathrm{sec}$. period was assumed. 

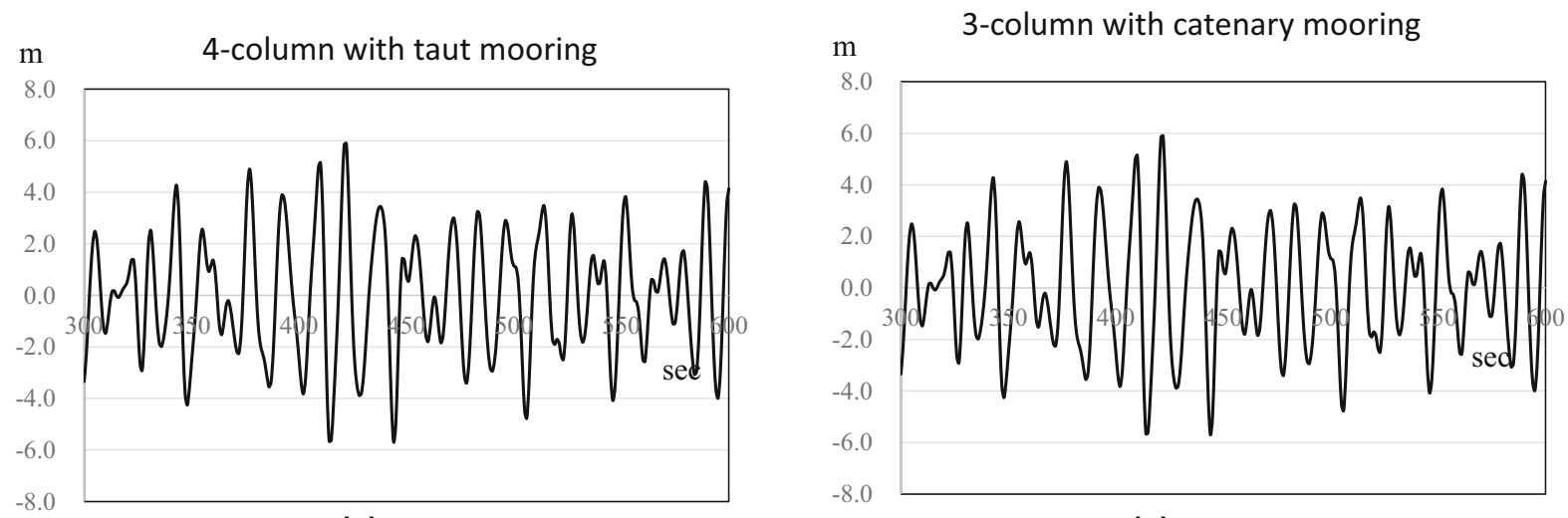

$\operatorname{deg}$

(a) wave

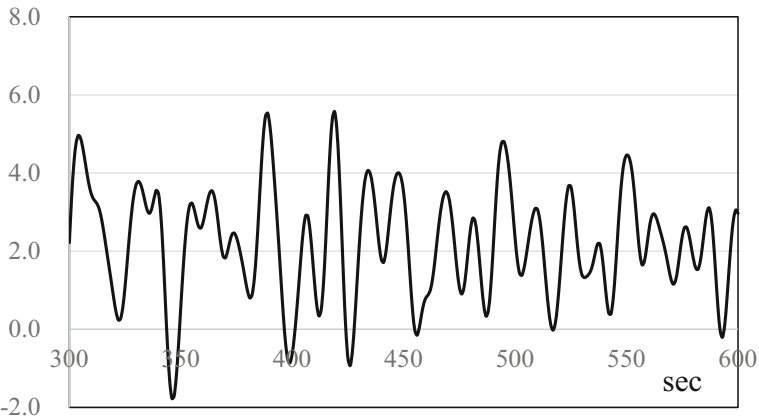

(b) pitch

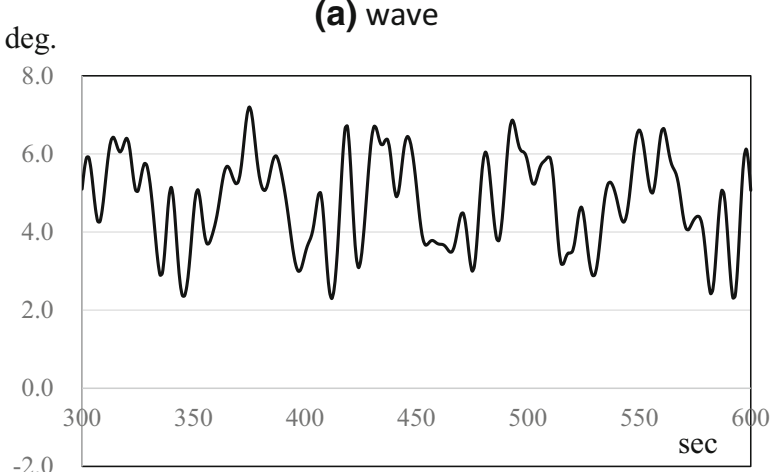

(b) pitch

Fig. 18 Time series in expected severest sea state at offshore Greece $\left(H_{1 / 3}=9.82 \mathrm{~m}, \mathrm{~T} 0=12.64 \mathrm{sec}\right.$, wind $\left.\left(u_{w 0}\right): 40 \mathrm{~m} / \mathrm{s}\right)$. a Wave. b Pitch

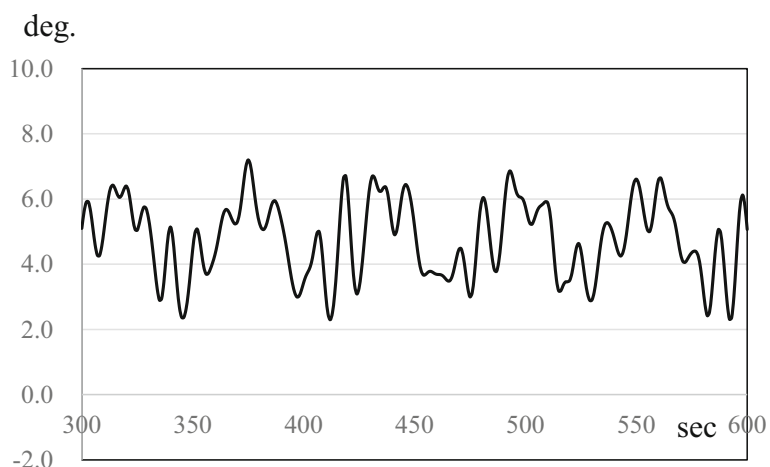

(a) with time-wise variation of wind speed

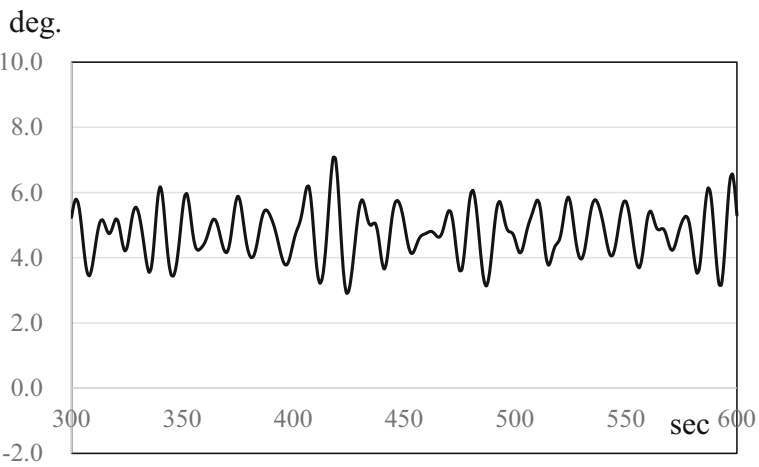

(b) without time-wise variation of wind speed

Fig. 19 Pitch time series with and without time-wise variation of wind speed $\left(H_{1 / 3}=9.82 \mathrm{~m}, \mathrm{~T} 0=12.64 \mathrm{sec}\right.$, wind : $\left.40 \mathrm{~m} / \mathrm{s}\right)(3-\mathrm{column}$ supported SWVAWT moored with catenary lines). a With time-wise variation of wind speed. $\mathbf{b}$ Without time-wise variation of wind speed

From Figs. 17 and 18, it can be reconfirmed that the motion characteristics indicated already in this paper are in effect, that is, steady tilt is significantly larger if moored by catenary lines. As for the time-varying motion responses, they are very small in the medium sea state regardless of the mooring systems. Even in the expected maximum sea state, the time-varying motion responses are reasonably small from the viewpoint of the safety of the floating systems.

Overall, the maximum inclinations (steady part + timevarying part) are about $7^{\circ}$ for the 3 -column catenary moored
SWVAWT and about $6^{\circ}$ for the 4-column taut moored SWVAWT, both of which may be acceptable from the viewpoint of their safety.

Besides these motion characteristics, one noticeable feature observed in the time series of pitch motions of the 3-column SWVAWT moored by catenary lines is the slowly varying component of significant amplitude. This turned out to be caused by the slow variation of the wind speed induced by the second term of the right-hand side of Eq. (15). This is confirmed in Fig. 19, in which the pitch motions in wind 


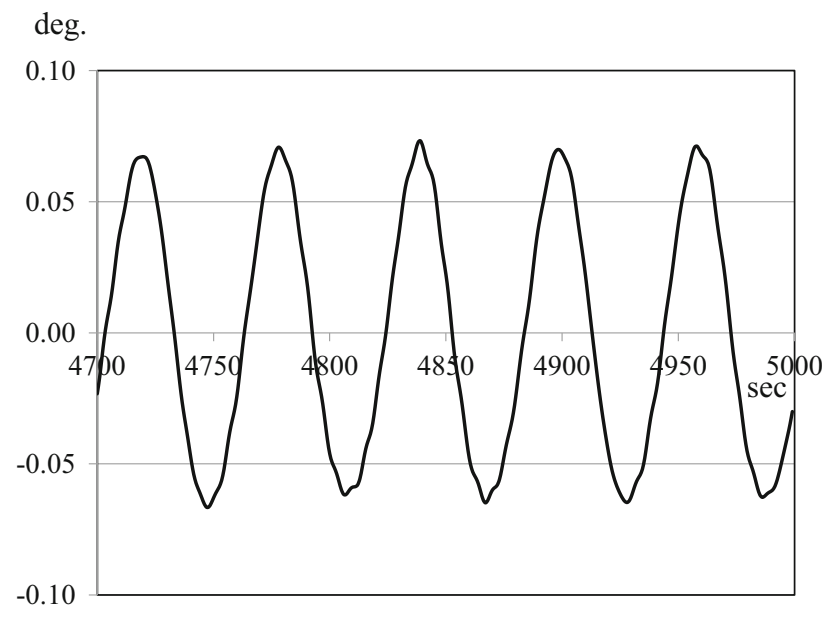

Fig. 20 Gyro effect on pitch motions (Difference between pitch motions with and without gyro effect) $\left(H_{1 / 3}=2.75 \mathrm{~m}\right.$, T0 $=$ $5.06 \mathrm{sec}$, wind $=25 \mathrm{~m} / \mathrm{s}$ ) (3-column supported SWVAWT moored by catenary lines)

of time-varying speed represented by Eq. (15) and those in wind of fixed speed are compared. It is apparent that the slow variation of pitch motions disappear in wind of fixed speed. Although real wind speed may vary in a more complicated manner than represented by Eq. (15), this fact suggests that such slow variations of significant amplitude could be induced by slow variations of wind speed if the corresponding floating structure is moored with relatively small restoring coefficients.

\subsubsection{Gyro effect on motions}

Motions of a floating SWVAWT are affected more or less by the gyroscopic effect induced by the rotations of the SWVAWT as described in Sect. 3.1(7). Figure 20 shows an example result on how such gyroscopic moment affects the pitch motions. (The figure shows the difference between pitch motions with and without the gyro effect. In calculating without gyro effect, the term $F_{w t_{i}}$ in Eq. (1) was neglected.)

As observed, the effect is very small, less even in the relatively high wind of the cut-out speed $25 \mathrm{~m} / \mathrm{s}$. It is almost periodic with constant amplitude, which suggests that the relevant effect comes from the time-varying part of the wind speed (second term of the right-hand side of Eq. (15)). This is confirmed by the fact that, if the wind speed is assumed to be constant, the periodic part observed in Fig. 20 disappears, and, thus, the gyro effect becomes even smaller.

Then, it may be concluded that the gyro effects of the SWVAWT are very small and practically negligible in the present design.

These results reconfirm the advantage of a vertical axis wind turbine mentioned in Sect. 2.2.

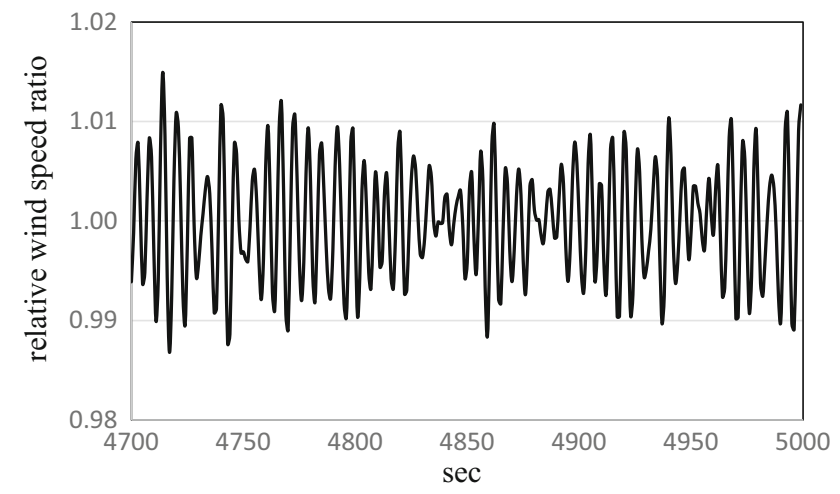

Fig. 21 Time series of the ratio of relative wind speed to absolute wind speed (4-column taut moored SWVAWT, $H_{1 / 3}=2.75 \mathrm{~m}, T_{1}=$ $5.06 \mathrm{sec}$, windspeed $=12 \mathrm{~m} / \mathrm{s}$ )

\subsection{Motion effects on power generation}

One of the disadvantages of a floating wind turbine compared to a fixed wind turbine is that the motions could negatively affect the power generated as:

1. Wind speed relative to the wind turbine varies due to wave induced motions, which, in turn, results in the time-wise variation of generated power.

2. Wind speed incident perpendicular to blades is reduced due to the inclination of a wind turbine, which, in turn, reduces the power generated.

Figure 21 shows an example of the time series of the ratio of relative wind speed to absolute wind speed when the wind speed is $12 \mathrm{~m} / \mathrm{s}$. The ratio remains very close to unity, the deviation from 1 is contained within $1 \%$ at most.

On the other hand, referring to Fig. 17, the maximum inclination in medium sea state $\left(H_{1 / 3}=2.75 \mathrm{~m}, T_{1}=\right.$ $5.06 \mathrm{sec}$, wind $=12 \mathrm{~m} / \mathrm{s}$ ) is $1.0^{\circ}$. for the catenary-moored 3-column SWVAWT and $0.5^{\circ}$. for the taut-moored 4-column SWVAWT at most.

Thus, considering that the power generated by a wind turbine is proportional to the cube of incident wind speed and assuming the incident wind speed is wind speed times the cosine of inclination, possible maximum power generation reduction due to motions may be estimated as follows.

1. $3.0 \% \Leftarrow 1-\{0.99 \times \cos (0.5 \mathrm{deg})\}^{3}$ for the 3 -column SWVAWT moored by steel-chain catenary lines

2. $3.0 \% \Leftarrow 1-\{0.99 \times \cos (1.0 \mathrm{deg})\}^{3}$ for the 4 -column SWVAWT moored by polyester taut lines

\subsection{Expected annual electricity yield}

Considering the power curve of the VAWT, as well as the probability function of occurring wind speeds as resulting 
from the statistical analysis of wind data gathered for the case study site, the annual power output of the system is calculated. The following formula was used:

$\mathrm{APO}=\int_{0}^{\infty} P(u) f(u) d u \times 365 \times 24(\mathrm{MWh})$,

where, $P(u)$ power output as a function of wind speed (MW)

$f(u)$ probability function of wind speeds' occurrence

$u$ wind velocity $(\mathrm{m} / \mathrm{s})$

The calculation that resulted showed the annual power output of the system of one floating VAWT operating at the offshore central Aegean Sea averaged over the 11 years would be equal to $5.66 \mathrm{GWh}$. Considering the rated power of the SWVAWT assumed in this study is $2 \mathrm{MW}$ as was shown in Table 1, with this annual electricity yield, the capacity factor is $32.3 \%$, which is reasonably high if compared to the usual capacity factor $20 \%$ of land-based wind turbines. [The long-term average value of the capacity factor of a wind park of total rated power $825 \mathrm{~kW}$ installed on the Lesbos Island in the Aegean Sea during 1995-2004 was slightly above $12.5 \%$ (Kavadias et al. 2009).]

During the 11 years 2001-2012, there were years that do not have measurements over long periods 3-4 months and some that were better represented. Among them, since 2011 was a year with almost full data availability, a more detailed analysis was performed for 2011 as a representative year in order to calculate the monthly electricity yield and respective capacity factor over the course of one year. As shown in Table 10, the annual yield in 2011 turned out to be $7.0 \mathrm{GWh}$ with capacity factor $40 \%$. The results of the monthly capacity factors, as shown in Table 10, ranged from 20 to $64 \%$, with an extremely significant value of $53 \%$ (one of the three highest monthly electricity yields) during the month of August,

Table 10 Monthly electricity yield for year 2011

\begin{tabular}{lll}
\hline Month & $\begin{array}{l}\text { Electricity yield } \\
(\mathrm{MWh})\end{array}$ & $\begin{array}{l}\text { Capacity factor } \\
(\%)\end{array}$ \\
\hline January & 480.1 & 32 \\
February & 405.8 & 30 \\
March & 593.9 & 40 \\
April & 915.0 & 64 \\
May & 435.1 & 29 \\
June & 373.6 & 26 \\
July & 297.3 & 20 \\
August & 788.5 & 53 \\
September & 665.7 & 46 \\
October & 726.4 & 49 \\
November & 894.2 & 62 \\
December & 437.0 & 29 \\
Total & $\sim 7.0 \mathrm{GWh}$ & 40 \\
\hline
\end{tabular}

Table 11 Annual energy demand in a residential sector (quoted from IslePact 2013)

\begin{tabular}{lll}
\hline Island & Population & $\begin{array}{l}\text { Annual energy demand } \\
\text { Residential sector }(\mathrm{GWh})\end{array}$ \\
\hline Naxos & 17,646 & 31 \\
Mykonos & 9320 & 26 \\
\hline
\end{tabular}

which happens to be the month with the greatest peak in power demand due to mainly two reasons: August's high tourist season and summer's hottest temperatures resulted in much increased cooling needs.

The above show that the present floating wind turbine system deployed at the offshore site of Aegean Sea islands cannot only supply a great load of energy safely and in a constant way, but also, and more importantly, when mostly needed.

\subsection{Feasibility of power supply to islands from offshore Greece}

The offshore site under consideration is close to two major population centers that are the islands of Mykonos and Naxos, each one with different characteristics. Naxos is the biggest island of the Cyclades complex with 17646 habitants, while Mykonos is an island with great energy fluctuations due to the vast amount of tourists that visit the island despite the small number of 9320 habitants. Table 11 shows the island's residential energy demand per year.

If compared to the energy demand of the annual energy output of the floating SWVAWT system, it can be concluded that one floating VAWT system can provide $18 \%$ of Naxos' electricity demand and $21 \%$ for Mykonos. Consequently, a park of at least six floating SWVAWTs can give total energy independence to the biggest island in the complex in terms of electricity demand of the habitants, provided that a sufficient energy storage system is available, although, in practice, actual development is highly dependent on the cost of energy, the analysis of which is missing in the present study.

\section{Conclusions}

Two concept designs of floating vertical-axis wind turbines, that is, a floating wind turbine supported on a 3-column semi-submersible and that supported on a 4-column semisubmersible, were proposed and dynamic motion response analyses of the proposed floating wind turbines in waves and winds were carried out by using the developed computer code. The sea states assumed in the analyses were determined while referring to the waves and winds measured for 11 years at offshore Greece. 
Motion responses of the designed floating turbines in waves and winds including the steady excursion and tilt were calculated. As for the mooring system, a steel-chain catenary mooring system and a polyester taut mooring system were chosen as possible candidates.

The dynamic motions in waves and winds of the designed wind turbines are very small in the medium sea state. Even in the expected maximum sea state, the dynamic motions are reasonably small from the viewpoint of the safety of the floating systems.

Among the two floating turbines designed in the present study, the 4-column supported wind turbine moored by taut polyester lines may be an appropriate candidate for a floating vertical-axis wind turbine of large rated capacity ( $2 \mathrm{MW}$ in this study), for the following reasons.

1. The burden of the semi-submersible to sustain the weight of mooring lines is mitigated considerably if moored by polyester lines, because the weight of the lines in water can be almost zero.

2. The steady excursion and steady tilt in waves and winds, especially steady excursion, can remain reasonably small if moored by taut lines.

3. The steady yaw in wind could be excessively large if moored by catenary lines, whereas it can be kept reasonably small if moored by taut lines.

4. The natural periods of dynamic motion could be designed far off the relevant period range of the wave power spectrum even if moored by taut mooring lines.

If the polyester mooring lines are used, the catenary mooring system is not possible, because their weight in water is almost zero and thus appropriate restoring forces cannot be obtained if they are deployed in catenary lines. Therefore, they need to be moored as taut lines, which, in turn, shortens the natural periods of motion. In order to avoid this, the total weight of the floating wind turbine needs to be increased, which is the reason why the 4-column semi-submersible instead of the 3-column semi-submersible was chosen in the case of taut mooring lines.

After all, it may be concluded that motions of floating wind turbines are quite susceptible to where the natural periods of the motions are located in their RAOs, and, thus, their weight and hydrostatic and mooring restoring coefficients need to be designed so that the natural periods are far off the relevant wave period range of the wave power spectrum at the site of their deployment.

The central Aegean Sea state was processed statistically and showed very good wind conditions combined with small wave heights. Under the site specific wind characteristics, the behavior of the system may be referred to as trustworthy. The average annual power output estimated for the years of 2001-2012 was 5.66 GWh (capacity factor $32.3 \%$ ), which suggests that the total annual residential energy demand of the surrounding island populations can be covered at a percentage of over $18 \%$ by the operation of only one floating SWVAWT system. A park of six floating turbines should be enough to offer power independence to the habitants. Even for severe sea states, the proposed systems can be considered safe. On those terms, the site is an excellent candidate for offshore development. In practice, however, since actual development is highly dependent on the cost of energy, the cost analysis, which is missing in the present study, is needed.

Acknowledgments The sea and wind data of the central Aegean Sea used in this work were provided by the Hellenic Center for Marine Research in Greece. The authors appreciate very much the permission given for the use and the publication of the data in this study.

\section{References}

Ashwill TD (1992) Measured data for the Sandia 34-meter vertical-axis wind turbine, Technical Report SAND91-2228, Sandia National Labs., Albuquerque, NM (United States)

Blonk DL (2010) Conceptual design and evaluation of economic feasibility of floating vertical axis wind turbines-Public Version, M.Sc. Thesis, Delft University of Technology

Borg M, Shires A, Collu M (2014a) Offshore floating vertical axis wind turbines, dynamics modelling state of the art, part 1: aerodynamics. Renew Sustain Energy Rev 39:1214-1225

Borg M, Shires A, Collu M (2014b) Offshore floating vertical axis wind turbines, dynamics modelling state of the art, part 2: mooring line and structural dynamics. Renew Sustain Energy Rev 39:12261234

Borg M, Shires A, Collu M (2015) Offshore floating vertical axis wind turbines, dynamics modelling state of the art, part 3: hydrodynamics and coupled modelling approaches. Renew Sustain Energy Rev 46:296-310

Cummins WE (1962) The impulse response functions and ship motions. Schiffstechnik 9:101-109

Fowler M, Bull D, Goupee A (2014) A comparison of platform options for deep-water floating offshore vertical axis wind turbines: an initial study, Sandia Report, Sandia National Laboratories

Goda Y (2002) A simplified wind wave estimation based on Wilson's prediction formulas. Fellow of JSCE, Dr. Eng., ECOH Corp., ECOH/YG Technical Paper No.1, pp 1-3

Hatziargyriou ND, Tsikalakis A, Androutsos A (2006) Status of distributed generation in the Greek Islands. IEEE, Power EnginHYPERLINK

Hoerner SF (1965) Fluid-Dynamic Drag, Published by the Author. http://ieeexplore.ieee.org/xpl/mostRecentIssue.jsp? punumber=11204eering Society General Meeting, Montreal, Canada: pp 1-6. doi:10.1109/PES.2006.1709075

IslePact, Sustainable Energy Actions for Islands (2013) Accessed online at: http://www.islepact.eu/html/index.aspx. Accessed date July 2013

Jonkman JM (2007) Dynamic modeling and loads analysis of an offshore floating wind turbine, Technical Report NREL/TP-50041958

Jonkma JM, Matha D (2011) Dynamics of offshore floating wind turbines-analysis of three concepts. Wind Energy 14:557-569

Kanner S, Yeung RW (2014) Innovation for a reduction of the yaw moment on a floating platform with a vertical-axis wind turbine. In: Proceedings of ASME $201433^{\text {rd }}$ International Confer- 
ence on Ocean, Offshore and Arctic Engineering (OMAE2014), OMAE2014-23819

Katsoulis BD (1993) A survey on the assessment of wind energy potential in Greece. Theor Appl Climatol 47(1):51-63. doi:10.1007/ BF00868895

Kavadias KA, Kapsali M, Kaldellis JK (2009) An integrated computational method for the optimum sizing of a wind-based pumped hydro storage system, European Wind Energy Conference 2009

Kobayashi M, Shimada K, Fujihira T (1985) A simulation program of dynamic response of a moored structure subjected to compound external force. Technological Bulletin of Mitsui Engineering \& Shipping Co., Ltd., No. 125:10-16

Lefebvre S, Collu M (2012) Preliminary design of a floating support structure for a 5MW offshore wind turbine. Ocean Eng 40:15-26
Paraschivoiu I (1988) Double-multiple stream tube model for studying vertical-axis wind turbines. J Propuls Power 4(4):370-377

Pinkster JA (1974) Low frequency phenomena associated with vessels moored at sea. Society of Petroleum Engineering of AIME, Spring Meeting, SPE 4837

POSEIDON Operational Oceanography System-Hellenic Center for Marine Research (HCMR). (2013) Accessed online at: http:// poseidon.hcmr.gr/. Accessed date Jul 2013

Shibuya A (2006) Performance estimation of a SWVAWT by means of two stage multi-streamtube analysis with divergence taken into account, Master Thesis, Kogakuin University. (in Japanese)

Wakisaka E (2011) Performance evaluation of a SWVAWT by means of numerical analysis utilizing DES turbulence model, Master Thesis, Kogakuin University. (in Japanese) 